\title{
On the Dissolution Process of Manganese and Iron in Molten Aluminum
}

\begin{abstract}
GHADIR RAZAZ and TORBJÖRN CARLBERG
The dissolution of $\mathrm{Mn}$ and $\mathrm{Fe}$ in liquid $\mathrm{Al}$ presents a challenge due to their high melting points and low diffusivity. A literature review reveals that the existing knowledge of the processes involved in the dissolution of both $\mathrm{Fe}$ and $\mathrm{Mn}$ in liquid $\mathrm{Al}$ is rather ambiguous. Thus, this work aimed to obtain more detailed insights into the dissolution behavior of $\mathrm{Mn}$ and $\mathrm{Fe}$ in various $\mathrm{Al}$ melts. The results of the Mn dissolution tests showed that three intermediate phases were involved in the dissolution process, all of which exhibited a smooth interface between $\mathrm{Mn}$ and the liquid. These three phases were identified as the $\gamma_{2}, \mathrm{Al}_{11} \mathrm{Mn}_{4}$, and $\mu$ phases which grow slowly, penetrating the Mn particles. The results of the Fe dissolution tests showed that in pure $\mathrm{Al}$, the $\mathrm{Al}_{5} \mathrm{Fe}_{2}$ phase dominates the dissolution process and penetrates the $\mathrm{Fe}$ particles. The addition of $\mathrm{Ti}$ into the molten $\mathrm{Al}$ alters the intermetallic compound formation by replacing $\mathrm{Al}_{5} \mathrm{Fe}_{2}$ by $\mathrm{Al}_{2} \mathrm{Fe}$. The addition of $\mathrm{Si}$ significantly inhibited the $\mathrm{Fe}$ dissolution kinetics. $\mathrm{A}$ theoretical approach based on Ficks' law was used to explain the experimentally obtained Mn and $\mathrm{Fe}$ dissolution rates. It showed that the surface area and shape of the additives significantly affected the dissolution processes.
\end{abstract}

https://doi.org/10.1007/s11661-019-05120-4

(c) The Author(s) 2019

\section{INTRODUCTION}

THE alloying elements $\mathrm{Mn}$ and Fe can be added into an Al melt either as discrete particles or as powder compacts of master alloys consisting of various fractions of the alloying element and aluminum. ${ }^{[1,2]}$ The dissolution of compacts occurs in three steps. First, during the incubation period, the aluminum inside the compact starts to melt. Next, the Al melt reacts with the alloying-element particles exothermally to form various intermetallic compounds. Eventually, the compact is disintegrated and disperses into the melt for further dissolution..$^{[3,4]}$

$\mathrm{Mn}$ and $\mathrm{Fe}$ are important alloying additions for industrial Al alloy production. However, achieving complete dissolution of these elements in liquid Al has been a challenge owing to their high melting temperatures and low solid solubilities $\left(0.05\right.$ and 1.8 wt pet, ${ }^{[5,6]}$ respectively). Common issues in many cast houses are low dissolution rates and low recovery. ${ }^{[1,4]}$ In fact, the dissolution of these alloying elements involves the formation of intermetallic phases. The formation and growth of these phases at the interface between the solid

GHADIR RAZAZ and TORBJÖRN CARLBERG are with the Department of Natural Science, Mid Sweden University, 85170 , Sundsvall, Sweden. Contact e-mails: Ghadir.razaz@miun.se; Torbjorn.carlberg@miun.se

Manuscript submitted October 29, 2018.

Article published online January 16, 2019 additives and liquid metal are governed by complex diffusion conditions. ${ }^{[7]}$

Several studies have been performed focusing on the dissolution of $\mathrm{Fe}^{[5,7-10]}$ However, the dissolution of $\mathrm{Mn}$ in $\mathrm{Al}$ melt has not been investigated to the same extent. Nevertheless, in a previous work, the dissolution behavior of both $\mathrm{Fe}$ and $\mathrm{Mn}$ in $\mathrm{Al}$ melts has been addressed. ${ }^{[1]}$ It was shown that the morphology of the intermetallic compounds formed at the interface of solid $\mathrm{Fe}$ in liquid $\mathrm{Al}$ differs from that of the phases formed at the interface of solid Mn. It was observed that during Fe dissolution the intermetallic phases grow towards the solid $\mathrm{Fe}$ forming an irregular interface, while during $\mathrm{Mn}$ dissolution, the intermetallic phases grow outwards into the liquid Al matrix forming a smooth interface. ${ }^{[1]}$ During Fe dissolution, $\mathrm{Al}_{5} \mathrm{Fe}_{2}$ and $\mathrm{Al}_{3} \mathrm{Fe}$ were detected as the major and minor intermetallic phases, respectively, during Fe dissolution. ${ }^{[7-9]}$ Meanwhile, during Mn dissolution, $\mathrm{Al}_{4} \mathrm{Mn}(\mu)$ was the only observed intermetallic phase. ${ }^{[1]}$ Although the types of interfacial phases formed, their morphology, and thickness influence the dissolution rate and alloying yield ${ }^{[8,9]}$ a literature review shows that no detailed description of the dissolution process of $\mathrm{Fe}$ and $\mathrm{Mn}$ in liquid $\mathrm{Al}$ exists, which urges the clarification of these processes.

The purpose of this work is to improve the understanding of the dissolution process of $\mathrm{Mn}$ and $\mathrm{Fe}$ in liquid Al. Thus, its aim is to study the phase formations at the interfaces, the related interface morphologies, growth kinetics, and dissolution rates. ${ }^{[8,9]}$ Dissolution 
experiments have been performed with various $\mathrm{Mn}$ compacts and pure $\mathrm{Fe}$ additives in $\mathrm{Al}$ liquid. These experiments focused on determining the dissolution rates, as well as observing the formation and growth of the intermetallic compounds.

A previous work by the authors ${ }^{[3]}$ showed that the dissolution of $\mathrm{Mn}$ in $\mathrm{Al}$ melt decreases in the presence of other alloying elements, e.g., 0.12 pct Ti. Thus, it was of great interest to examine the effect of other alloying elements on the dissolution performance of both $\mathrm{Mn}$ and Fe in Al alloys. This was achieved by studying the dissolution of $\mathrm{Mn}$ and $\mathrm{Fe}$ in $\mathrm{Al}$ melts containing 0.12 pet $\mathrm{Ti}$ and 0.8 pet $\mathrm{Si}$.

\section{EXPERIMENTAL PROCEDURE}

Two different experimental investigations were carried out in this work: the first series of experiments investigated the dissolution rate; the second series studied the dissolution mechanisms focusing on intermetallic compound formation and growth. In addition, a post-mortem analysis was performed on the undissolved Mn compacts found in the bottom region of the crucibles after the termination of the dissolution-rate experiments.

\section{A. Analysis of the Dissolution Rate}

To study the dissolution rate of manganese and iron in molten aluminum, several sampling tests were performed with pure $\mathrm{Al}$ at the furnace temperature of 770 ${ }^{\circ} \mathrm{C}$. For each test, an alumina crucible containing $500 \mathrm{~g}$ of $\mathrm{Al}$ was placed in the furnace at the target temperature which was monitored by a thermocouple (K-type). When the melt reached the desired temperature, an adequate amount of $\mathrm{Mn}$ or Fe was added to obtain an alloying-element concentration of 1.5 pct. Subsequently, various samples were cast from the crucible into cylindrical molds, which consisted of holes of $25 \mathrm{~mm}$ diameter made in an insulated material and placed on a steel plate to obtain directed solidification. Samples were taken after 1, 2, 3, 5, 7, and 9 minutes, respectively. The samples were then analyzed by OES, Optical Emission Spectroscopy. For the first set of experiments, stirring was conducted for 5 seconds, while for every other set of experiments, stirring was performed for 3 seconds before the sampling. During the tests, the melt temperature dropped from $770{ }^{\circ} \mathrm{C}$ at the first sampling to $730{ }^{\circ} \mathrm{C}$ at the last, which gave an average temperature of $750{ }^{\circ} \mathrm{C}$. For the dissolution experiments of $\mathrm{Mn}$, the alloying element was added in the form of as-cast Mn flakes (100 pct $\mathrm{Mn}$ ) or $\mathrm{Mn}$ compacts made from powders with various Al contents: 10, 20, and 20 pct containing flux. Within the compacts, the dominating sizes of the powder are in the range of 400 to $500 \mu \mathrm{m}$. The dissolution of $\mathrm{Fe}$ was studied by adding 2-mm-thick pure Fe flakes made from compacted powder. All the additives used in this study are frequently used in industry. Mn and Fe were added to molten Al alloys of various compositions whose actual chemical compositions are given in Table I.
Tabe I. Chemical Composition of the Various Alloys (Weight Percent)

\begin{tabular}{lcccc}
\hline Alloy & $\mathrm{Si}$ & $\mathrm{Fe}$ & $\mathrm{Mn}$ & $\mathrm{Ti}$ \\
\hline Pure Al & 0.06 & 0.07 & 0.001 & 0.005 \\
Al-0.12 Pct Ti & 0.05 & 0.07 & 0.001 & 0.12 \\
Al-0.8 Pct Si & 0.8 & 0.08 & 0.005 & 0.006 \\
\hline
\end{tabular}

\section{B. Analysis of the Dissolution Mechanism}

To investigate the dissolution mechanism in more detail, $50 \mathrm{~g}$ of pure $\mathrm{Al}$ and Al-Ti-(0.12 pct Ti) were melted in cylindrical crucibles with a diameter of $35 \mathrm{~mm}$, giving a melt depth of $20 \mathrm{~mm}$ in a furnace at a temperature of $760{ }^{\circ} \mathrm{C} .{ }^{[3]}$ When the melt temperature stabilized, pieces of pure Mn flakes, Mn alloy flakes (60 pet Mn, 40 pet Al), and Mn compacts ( 90 pet Mn, 10 pct $\mathrm{Al})$ were added to the pure $\mathrm{Al}$ and $\mathrm{Al}-\mathrm{Ti}$ (0.12 pct Ti) to provide melts that exhibit supersaturated conditions (10 pct $\mathrm{Mn}$ ). Subsequently, the crucible was removed from the furnace after 8 minutes and cooled to room temperature with a cooling rate of $1^{\circ} \mathrm{C} / \mathrm{s}$. A similar procedure was carried out to investigate the dissolution mechanism of iron with the addition of $\mathrm{Fe}$ flakes into pure Al, Al-Ti (0.12 pct Ti), and Al-Si (0.8 pct $\mathrm{Si})$. Every collected sample was cut longitudinally, metallographically prepared, and etched using 1 pet $\mathrm{NaOH}$ at $60{ }^{\circ} \mathrm{C}$ for about 15 seconds. Then, the samples were examined by a stereo microscope, light optical microscope (LOM), and scanning electron microscope (SEM, MAIA3, Tescan) equipped with energy dispersive X-ray spectroscopy (EDX, AZtec).

\section{Post-mortem Analysis of Precipitations Found in the Al-Ti Alloys}

Previous works studied the formation of unwanted precipitations of $\mathrm{Mn}$-containing phases in $\mathrm{Al}$ melts that contained $\mathrm{Ti}^{[11]}$ This work further examines these precipitations in a similar alloy, i.e., alloy 1. In order to analyze the precipitations, the material remaining at the bottom of the crucible after a dissolution-rate test using 90 pet $\mathrm{Mn}$ compacts was investigated. This material solidified at ambient temperature after dissolution at $750{ }^{\circ} \mathrm{C}$ lasting 9 minutes. Subsequently, the solid was cut into longitudinal sections and studied by SEM and EDX.

\section{RESULTS}

\section{A. Dissolution Rate of Mn Compacts with Various Al Contents}

The dissolution rate of $\mathrm{Mn}$ from various compacts in pure $\mathrm{Al}$ at $750{ }^{\circ} \mathrm{C}$ is shown in Figure 1. The stirring duration before each sampling test was 3 seconds. The highest dissolution rate was for the compact with 80 pct Mn-containing flux. The Mn content reached its target concentration (1.5 pct $\mathrm{Mn}$ ) at the end of the dissolution test ( 9 minutes). The second highest dissolution rate was 


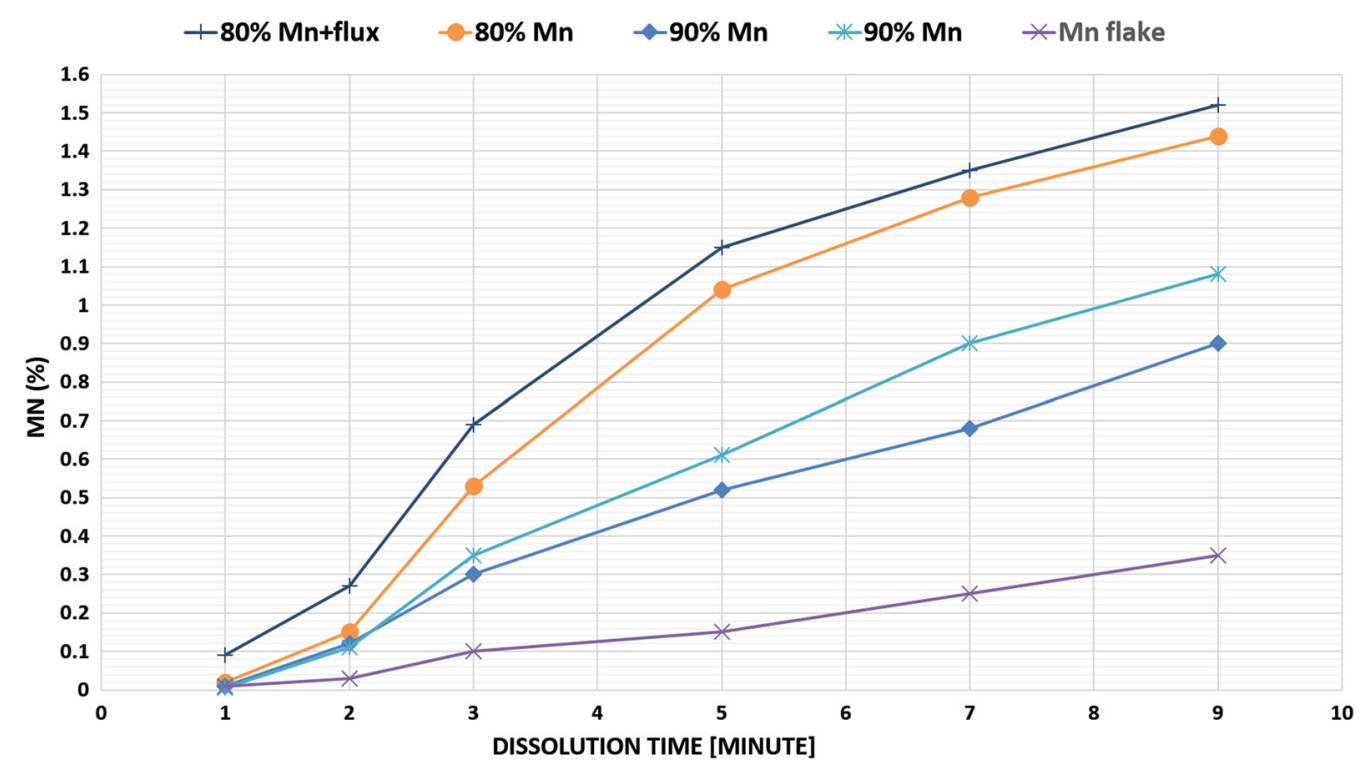

Fig. 1-Mn content of the melt during dissolution as a function of time after the addition of the various types of Mn compacts and a Mn flake into the pure $\mathrm{Al}$ melt and a stirring time of $3 \mathrm{~s}$.

obtained for the non-fluxed 80 pct Mn compact which showed a similar trend as the dissolution of the fluxed compact. The dissolution rate of the 80 pct $\mathrm{Mn}$ compacts was higher than that of the 90 pct $\mathrm{Mn}$ compacts. Clear differences in the dissolution rates could be observed after 2 minutes. The two 90 pct $\mathrm{Mn}$ experimental runs were made with the same parameters to show the level of reproducibility of the method. The lowest dissolution rate was observed from pure $\mathrm{Mn}$ flakes, which resulted in an $\mathrm{Mn}$ concentration of only about 0.4 pct at the end of the test ( 9 minutes), i.e., a similar value to the one obtained just after 2 minutes from the compacts.

The dissolution curves of each compact reveal a dissolution process characterized by an incubation time of 1-2 minutes with a subsequent rapid dissolution stage. Higher dissolution rates may be observed for the fluxed compacts during the incubation time, which shows the advantages of flux for accelerating the exothermic reaction within the compact. ${ }^{[4]}$

Only the dissolution curves of the 80 pct $\mathrm{Mn}$ compacts exhibited parabolic shapes towards the end of the dissolution test. However, they did not reach the saturation level (2 pct), i.e., the solubility limit for $\mathrm{Mn}$ at the respective temperature.

\section{B. Dissolution Rate of the 90 pct Mn Compact in Various Melt Compositions}

Two series of $\mathrm{Mn}$ dissolution experiments were performed by mixing compacts containing 90 pct $\mathrm{Mn}$ into two different melt compositions, pure $\mathrm{Al}$ and $\mathrm{Al}-\mathrm{Ti}$ $\left(0.12\right.$ pct Ti), respectively, at $750{ }^{\circ} \mathrm{C}$. The results are shown in Figure 2. ${ }^{[3]}$ The stirring time before each sampling test was 5 seconds compared with the 3 seconds used for obtaining the results shown in Figure 1. The dissolution rate of $\mathrm{Mn}$ in the Al-Ti (0.12 pct Ti) melt has substantially decreased compared with that in the pure Al melt. The dissolution curve obtained from the pure Al exhibits a parabolic shape towards the end of the test and the Mn content reaches 1.85 pct, which is close to the saturation value ( 2 pct). In Al-Ti $(0.12$ pct Ti), a 1 pet $\mathrm{Mn}$ concentration was reached only after 9 minutes, at which point the curve did not show signs of flattening out. This suggests that the dissolution was still at its early stage. Therefore, it can be concluded that the addition of 0.12 pet Ti lowers the dissolution rate of $\mathrm{Mn}$.

Furthermore, the higher dissolution rate obtained with the 5-second stirring (Figure 2) compared with the 3 -second stirring (Figure 1) for the 90 pct Mn compacts reinforces the importance of stirring, as was found in Reference 1.

\section{Dissolution Mechanism of Mn Compacts}

As mentioned in the introduction, the goal of this study was to describe the intermetallic phase formations in the Al-Mn system in detail. Therefore, experiments were performed in which most of the added solids did not dissolve. Thus, an interface between the solid and liquid phases was created that could be studied. With the addition of $\mathrm{Mn}$ corresponding to a concentration of 10 pct, it could also be assumed that local equilibrium (i.e., saturation) occurred in the proximity of the added flakes.

Results from the experiments with 90 pct $\mathrm{Mn}$ in pure $\mathrm{Al}$ for various immersion times of 2, 5, 8, and 16 minutes are shown in Figure 3. In the microstructures observed by the LOM, three layers are revealed around the Mn particles already after the 2-minute dissolution test, Figure 3(a). The thickness of these layers has slightly increased using longer immersion durations (e.g., 5, 8, and 16 minutes). This suggests that these layers have formed quickly around the $\mathrm{Mn}$ particles after immersion and then slowly grow during dissolution. Furthermore, 


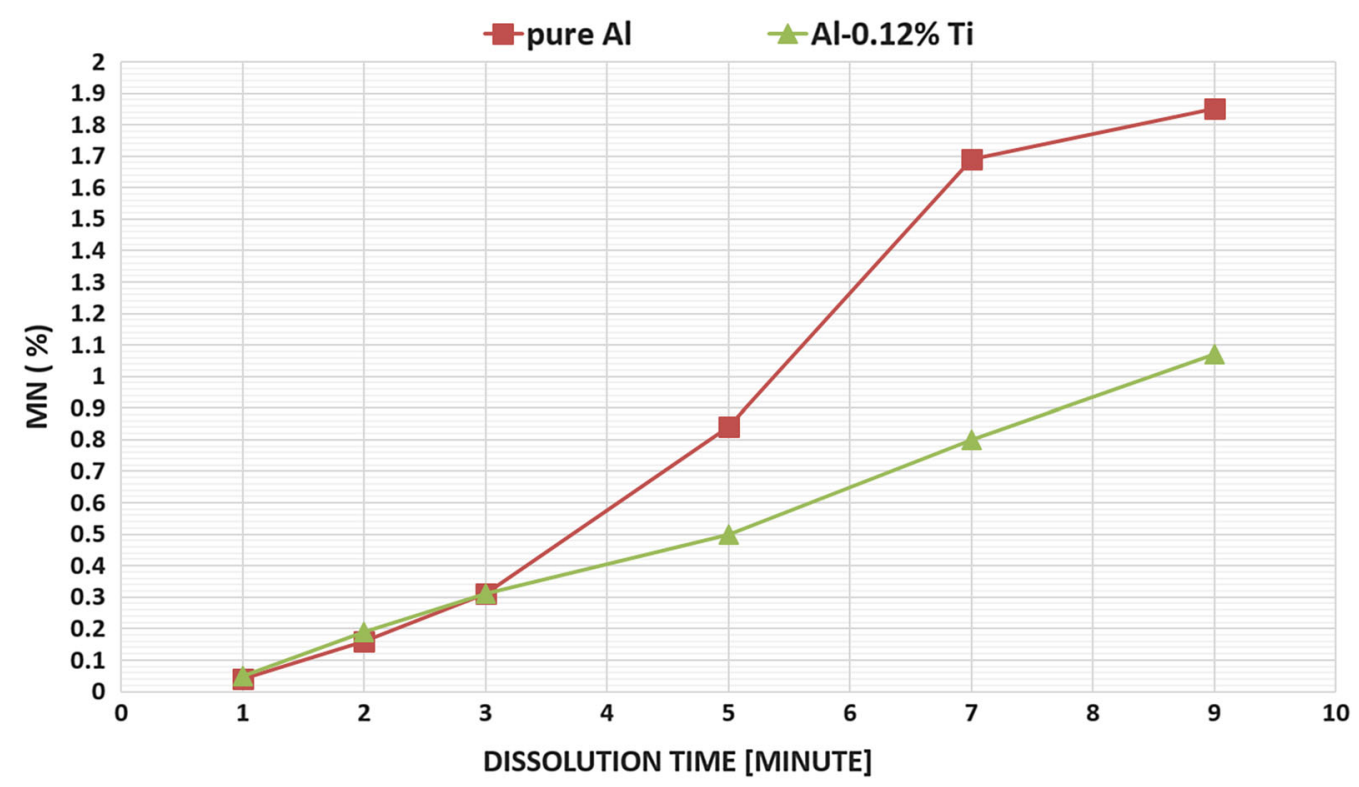

Fig. 2-Mn content of the melt during dissolution as a function of time after the addition of the Mn compact with 90 pct Mn content to two melts with different compositions and a 5-s stirring duration, from Ref. [3].

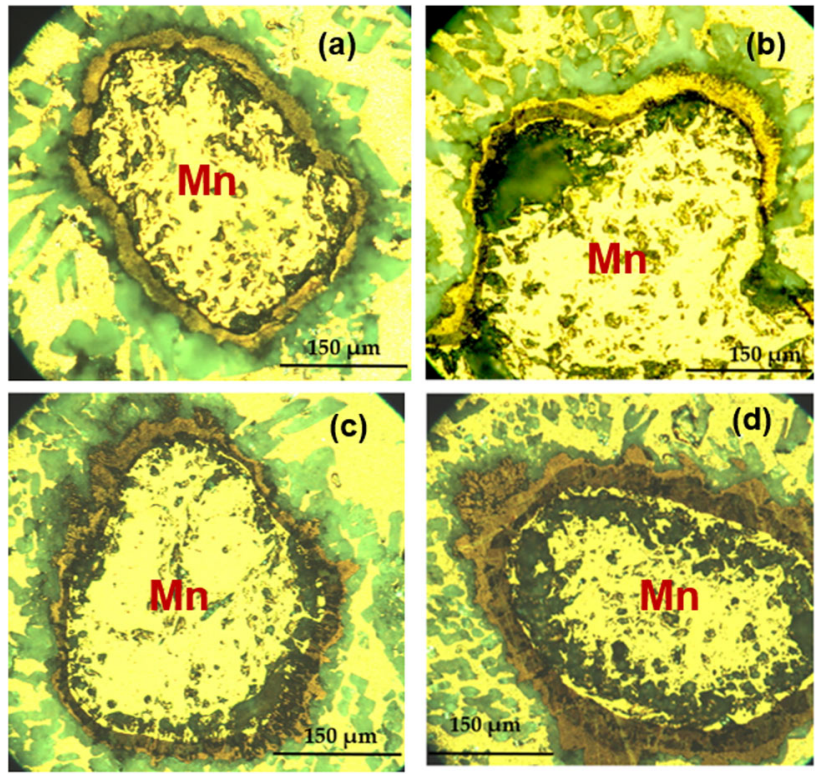

Fig. 3-LOM images of the intermetallic layers formed around Mn during the dissolution of the 90 pct $\mathrm{Mn}$ compact in pure $\mathrm{Al}$ after various dissolution durations: (a) 2 min, (b) 5 min, (c) 8 min, and (d) $16 \mathrm{~min}$.

voids, appearing as irregular dark green areas in Figure 3, form within the Mn particles close to the layer of the intermediate phases. The number and size of these voids seemed to increase during dissolution.

An SEM image and a line scan analysis by EDX of these layers after the 8-minute dissolution duration is shown in Figure 4. In Figure 4(a), four layers around the Mn compact are visible. In Figure 4(b), the EDX line scan shows the concentration levels. A sharp gradient is observed at the first layer adjacent to $\mathrm{Mn}$, showing its concentration change from 90 to $60 \mathrm{wt}$ pct.
The gradient is followed by 3 plateaus corresponding to 3 different Mn levels. Using the Al-Mn phase diagram shown in Figure 5, the following phases can be identified starting at $\mathrm{Mn}: \gamma 2, \mathrm{Al}_{11} \mathrm{Mn}_{4}$, and $\mu$, as shown in the upper part of Figure 4(b). For further arguments for the phase identification see Section IV-C. The morphology of the phases between the $\mu$ phase and $\mathrm{Al}$ exhibits high irregularity towards the Al liquid and has a different appearance characterized by numerous cracks and a lower $\mathrm{Mn}$ content than the adjacent $\mu$ phase. The intermetallic compounds observed around Mn significantly differ from what was reported in Reference 1 where only the $\mathrm{Al}_{4} \mathrm{Mn}$ phase was observed, which corresponds to the $\mu$ phase in the phase diagram shown in Figure 5. Therefore, the observed state is much more complex than has been previously reported.

Figure 6 shows the results of the dissolution of the 90 pct Mn compacts in the Al-Ti (0.12 pct Ti) melt. Again, four layers have formed around $\mathrm{Mn}$ after 8 minutes. These intermetallic layers can be identified using EDX and the phase diagram (in order from the Mn side): $\gamma 2$ (layer adjacent to $\mathrm{Mn}$ ), $\mathrm{Al}_{11} \mathrm{Mn}_{4}$, and $\mu$, which are the same phases as the ones observed in the pure Al liquid. Furthermore, a phase with an irregular and cracked morphology adjacent to $\mathrm{Al}$ - also similar to the one in pure Al-was observed. The only difference observed with the addition of $\mathrm{Ti}$ is that the gradient in the outer part of the Mn particle and in the $\gamma 2$ phase seems to be less steep than that in pure Al.

Voids can be observed in the Mn particles close to the intermetallic layers in Figures 4(a) and 6(a).

\section{Dissolution Mechanism of Pure Mn Flakes}

The microstructures of a pure Mn flake after 8 minutes of dissolution in pure $\mathrm{Al}$ and $\mathrm{Al}-\mathrm{Ti}(0.12$ pct Ti) are shown in Figures 7 and 8, respectively. Four layers 

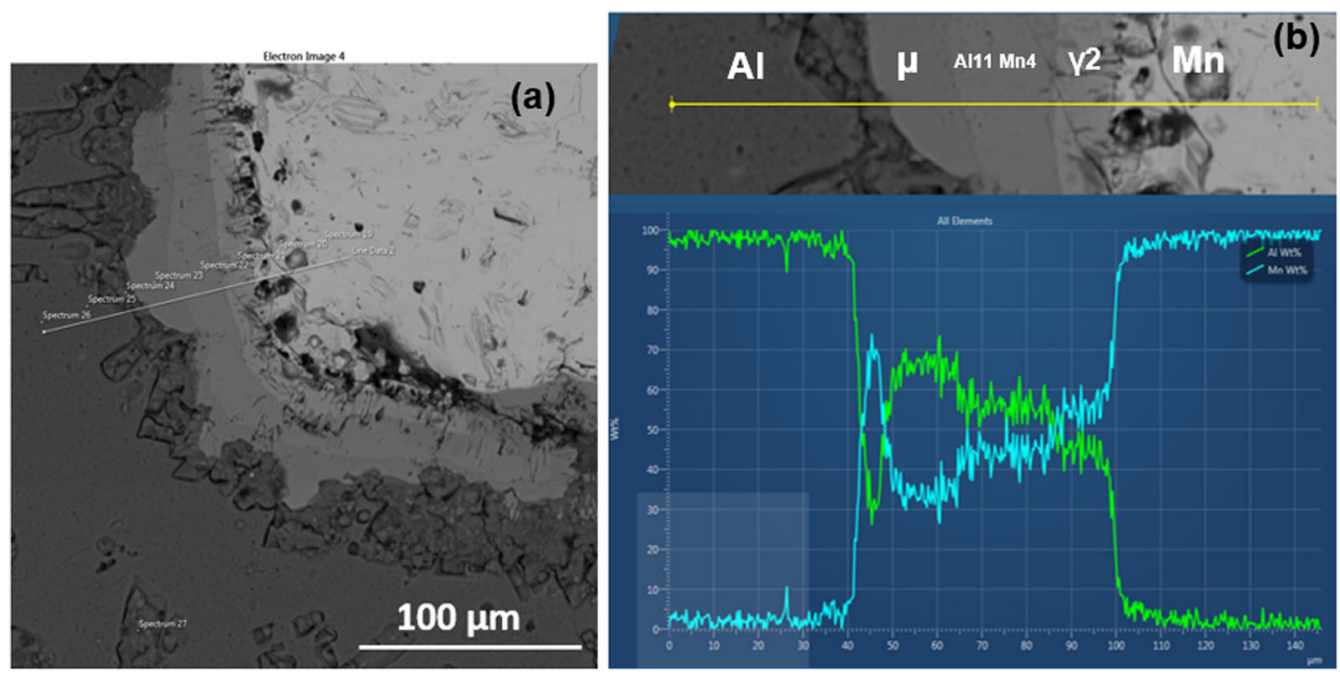

Fig. 4 - (a) Intermetallic phases formed at the interface of a piece of the 90 pct Mn compact and pure Al melt after 8 min, (b) corresponding EDX line scan. Full scale 100 wt pet.

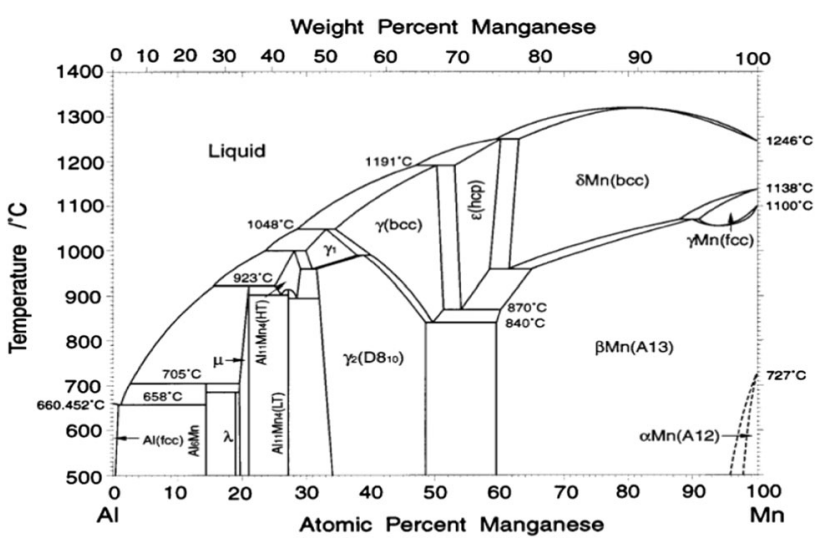

Fig. 5-Al-Mn equilibrium phase diagram, from Ref. [6] with permission.

have formed around the Mn flakes in both cases. In pure Al (Figure 7), the intermetallic layers identified by the EDX analysis are in the order: $\gamma 2$ (layer adjacent to $\mathrm{Mn}), \mathrm{Al}_{11} \mathrm{Mn}_{4}$, and $\mu$. In addition, a thick phase has precipitated on the melt side where the line scan ends. In addition, for the dissolution in Al-Ti (0.12 pet Ti), the same phases are identified, i.e., in the order: $\gamma 2$ (layer adjacent to $\mathrm{Mn}$ ), $\mathrm{Al}_{11} \mathrm{Mn}_{4}$, and $\mu$, with the scan ending in the thick phase on the liquid side. For the dissolution in the Ti-containing melt, the plateaus for the various phases are not as clearly identifiable as in the other samples. Nevertheless, the total thickness of the layers formed in this case is also significantly smaller, i.e., 10 $\mu \mathrm{m}$ compared to the $20 \mu \mathrm{m}$ observed in the pure $\mathrm{Al}$ melt. Furthermore, it can be observed that the dissolution of Mn flakes results in a smaller total thickness $(20 \mu \mathrm{m}$,
Figure 7(a) of the intermediate phases compared to the compact dissolution (about $50 \mu \mathrm{m}$, Figure 4a)).

In both Figures 7(a) and 8(a), voids and cracks can be observed in the Mn particles in the vicinity of the intermetallic layers.

\section{E. Dissolution Mechanism of 60 pct Mn Flakes}

Figure 9(a) shows the dissolution of a 60 pet Mn-Al (40 pct $\mathrm{Al}$ ) flake ( $\gamma 2$ phase) in pure $\mathrm{Al}$ after 8 minutes. Three intermediate phases have formed around the flake $(\gamma 2$ phase). These intermetallic layers were identified as $\mathrm{Al}_{11} \mathrm{Mn}_{4}$ (layer adjacent to $\gamma 2$ ) and the $\mu$ phase by the EDX line scan analysis shown in Figure 9(b). Furthermore, a precipitation was observed between the $\mu$ phase and $\mathrm{Al}$ exhibiting an irregular thickness.

Considering the dissolution mechanisms of pure $\mathrm{Mn}$ flakes, 60 pct $\mathrm{Mn}$ flakes, and Mn compacts, three common intermediate phases are involved in each dissolution process. These phases are $\gamma 2, \mathrm{Al}_{11} \mathrm{Mn}_{4}$, and the $\mu$ phase (in order from $\mathrm{Mn}$ to the liquid side). It can be seen from Figures 4, 7, and 9 that these three phases exhibit smooth surfaces. In addition, phases with irregular morphologies were observed at the interface between the $\mu$ phase and Al liquid in every case. These precipitated during the cooling process, as will be shown in the discussion.

Furthermore, the Mn dissolution tests showed that oxide films sometimes cover the interface between $\mathrm{Mn}$ and the Al melt. Figure 10(a) shows the dissolution of a pure Mn flake in the Al melt (Al-Ti (0.12 pctTi)) where the red arrow shows the location of the oxide film. The oxide film prevents the reaction between the Mn flake and $\mathrm{Al}$ melt. The clearly visible flat surface indicates the position of the original surface. Meanwhile, reactions between $\mathrm{Mn}$ and the $\mathrm{Al}$ melt on the sides have resulted 

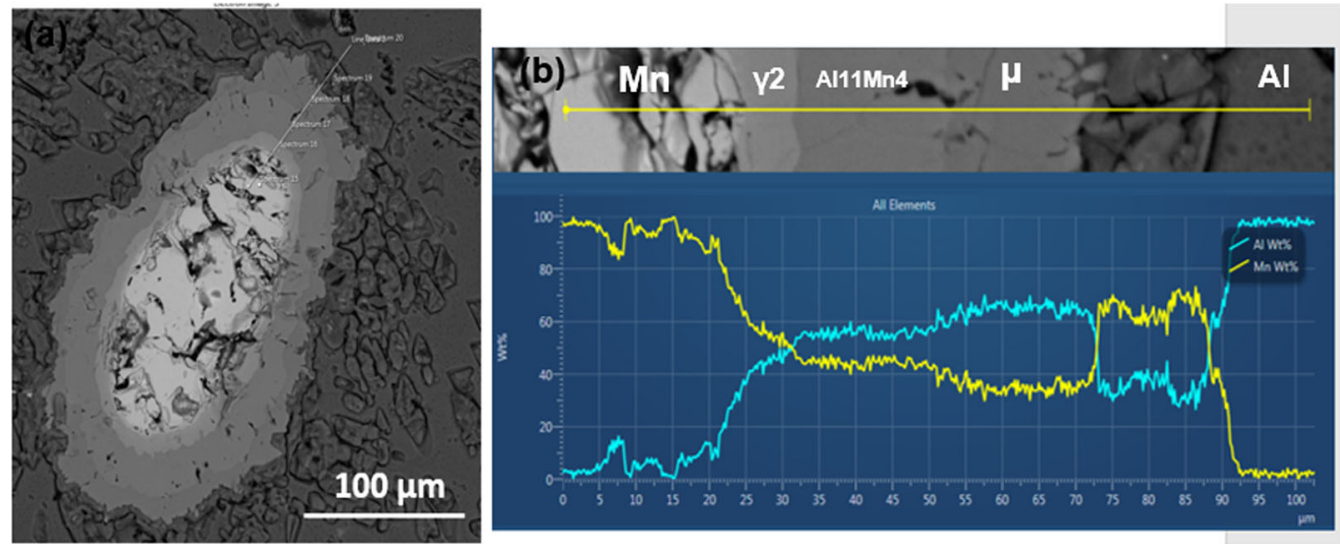

Fig. 6- (a) Intermetallic phases formed at the interface of a piece of the 90 pct Mn compact and Al-Ti (0.12 pct Ti) melt after 8 min, (b) corresponding EDX line scan. Full scale 100 wt pct.

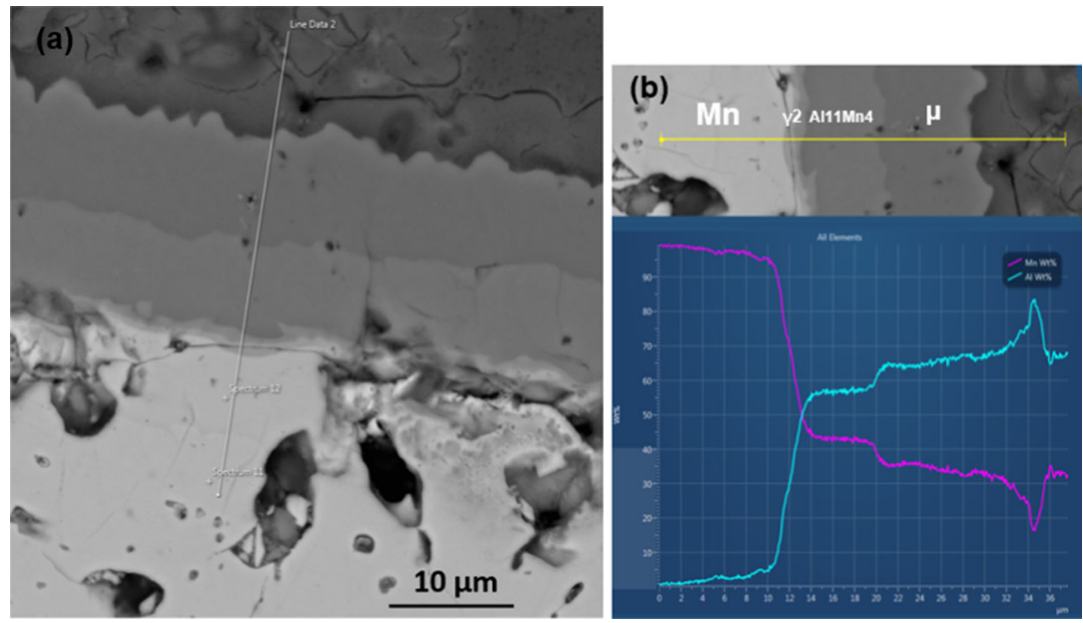

Fig. 7-(a) Intermetallic phases formed at the interface of a pure Mn flake and pure Al melt after 8 min, (b) corresponding EDX line scan. Full scale 100 wt pct.

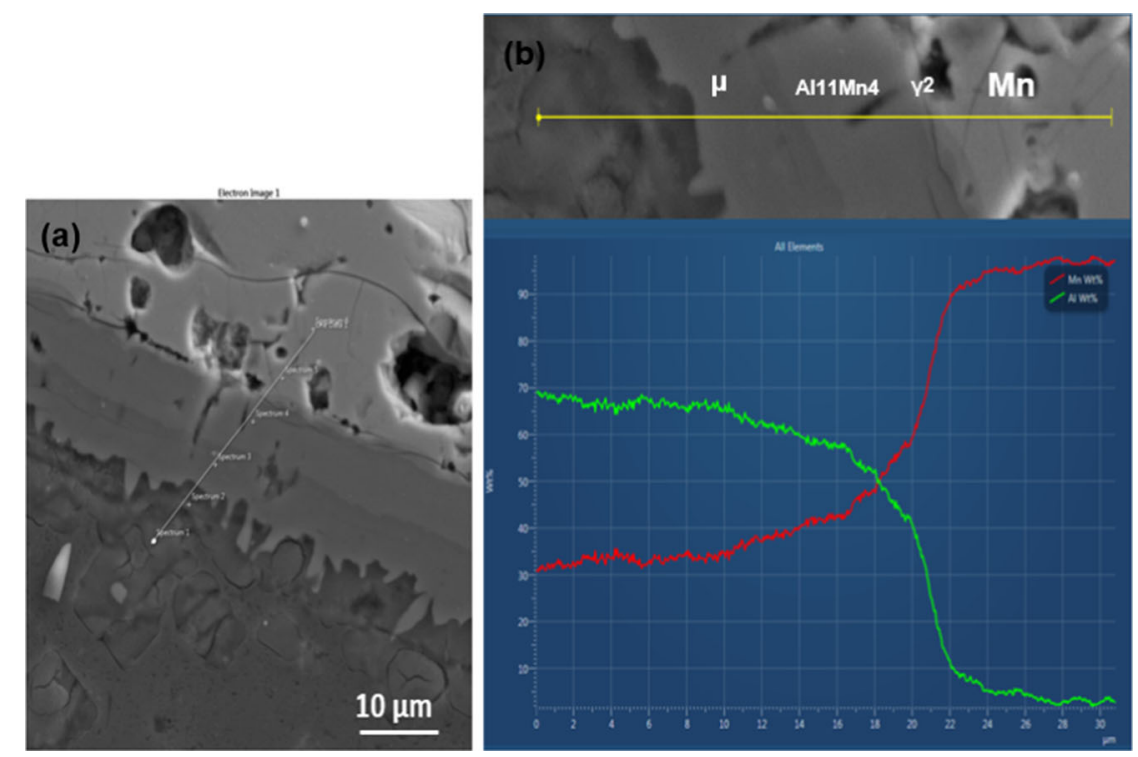

Fig. 8 - (a) Intermetallic phases formed at the interface of a pure Mn flake and Al-Ti (0.12 pct Ti) after 8 min, (b) corresponding EDX line scan. Full scale 100 wt pct. 


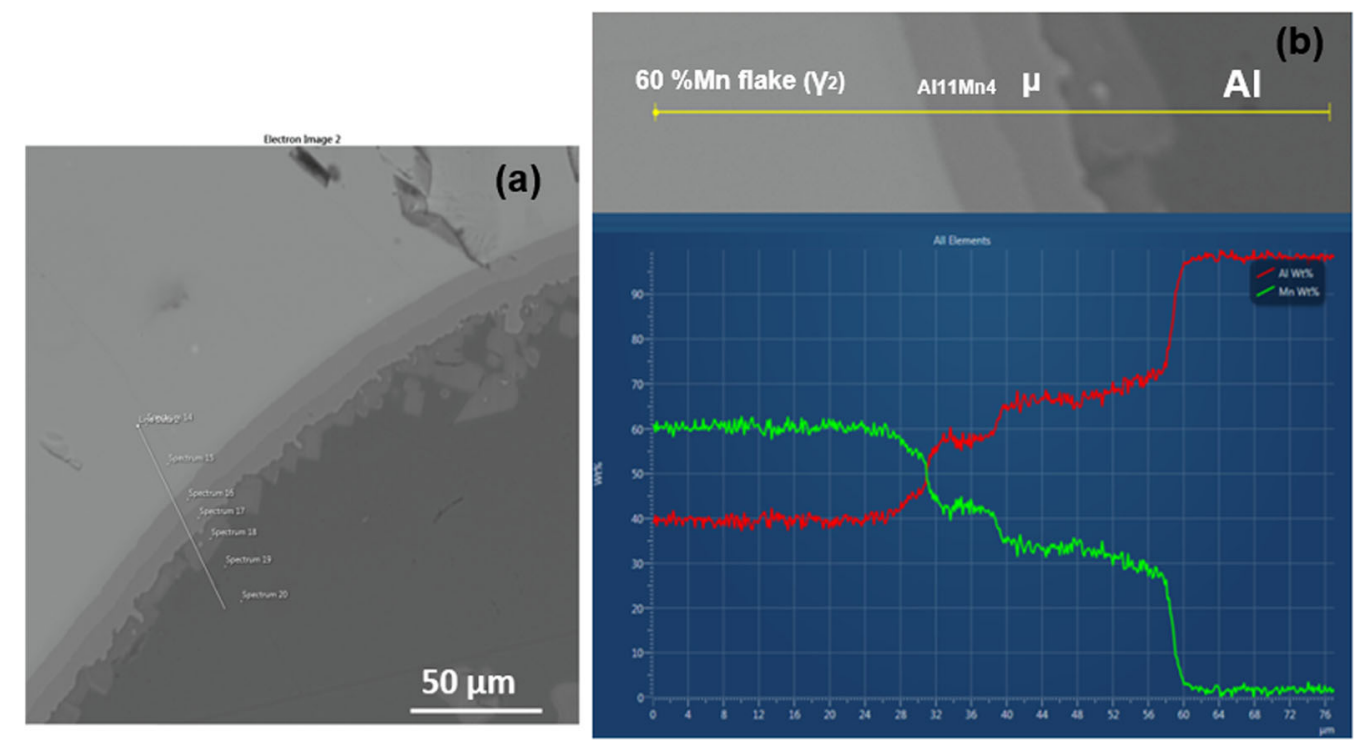

Fig. 9-(a) Intermetallic phases formed at the interface of a 60 pct Mn flake and pure Al after 8 min, (b) corresponding EDX line scan. Full scale 100 wt pct.
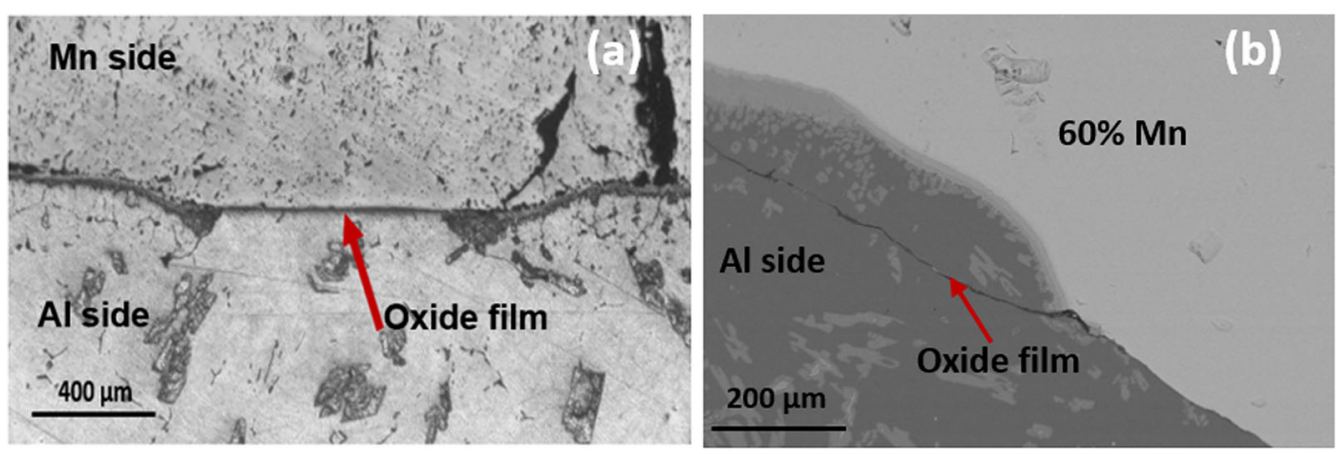

Fig. 10 - Oxide films at the interface between a Mn particle and the liquid Al: (a) LOM image of Mn dissolved in the Al-Ti (0.12 pct Ti), the arrow marks the oxide at the flat part of the unreacted interface, ${ }^{[3]}$ (b) SEM image of the interface between the 60 pct Mn alloy and liquid Al with an oxide film clearly visible (marked by an arrow) (Color figure online).

in the formation of intermediate phases and the dissolution of Mn. It can be calculated that about $90 \mu \mathrm{m}$ of the Mn flake has been dissolved in 8 minutes, as was reported in Reference 3. A similar case is shown in Figure 10(b) for the dissolution of a 60 pct Mn flake. Similarly, an oxide film prevented the reactions between $\mathrm{Mn}$ and $\mathrm{Al}$ on the right side of the figure. In the left side-where the melt has penetrated the oxide layer - the reactions have proceeded deep into the $\mathrm{Mn}$ solid.

Oxide layers are known to present a major barrier between Mn particles and the Al melt. ${ }^{[4]}$ It is accepted that oxides can delay the initiation of the reactions and thus the whole dissolution process. ${ }^{[4]}$

\section{F. Dissolution Rate of Fe Flakes in Various Melt Compositions}

Three series of dissolution-rate tests with iron flakes in liquid melts of pure $\mathrm{Al}, \mathrm{Al}-\mathrm{Ti}(0.12$ pct Ti), and $\mathrm{Al}-\mathrm{Si}$ (0.8 pct Si), respectively, were carried out. The results are shown in Figure 11. The dissolution rates of $\mathrm{Fe}$ in both pure $\mathrm{Al}$ and $\mathrm{Al}-\mathrm{Ti}(0.12$ pct Ti) show similar trends. However, the dissolution rate of $\mathrm{Fe}$ in $\mathrm{Al}-\mathrm{Si}(0.8$ pct $\mathrm{Si}$ ) is clearly lower. In addition, a strong increase in the dissolution rate is observed after 2 minutes in pure $\mathrm{Al}$ and $\mathrm{Al}-\mathrm{Ti}(0.12$ pet Ti), whereas in $\mathrm{Al}-\mathrm{Si}(0.8$ pct $\mathrm{Si})$ this rise occurs after 5 minutes, i.e., the incubation time is increased by the presence of Si. Furthermore, none of the dissolution-rate series exhibit the parabolic shape which generally characterized the dissolution completion. Hence, it can be concluded that the dissolution did not reach the targeted concentration $(1.5$ pct $\mathrm{Fe})$ in any of the series.

\section{G. Dissolution Mechanisms of Fe}

A microstructural investigation of the dissolution of Fe flakes in pure Al, Al-Ti (0.12 pct Ti), and Al-Si (0.8 pct $\mathrm{Si}$ ) after 8 minutes was performed. Figure 12 shows that two layers were formed around the Fe flake during the dissolution of Fe in pure $\mathrm{Al}$ : a thick layer adjacent to 


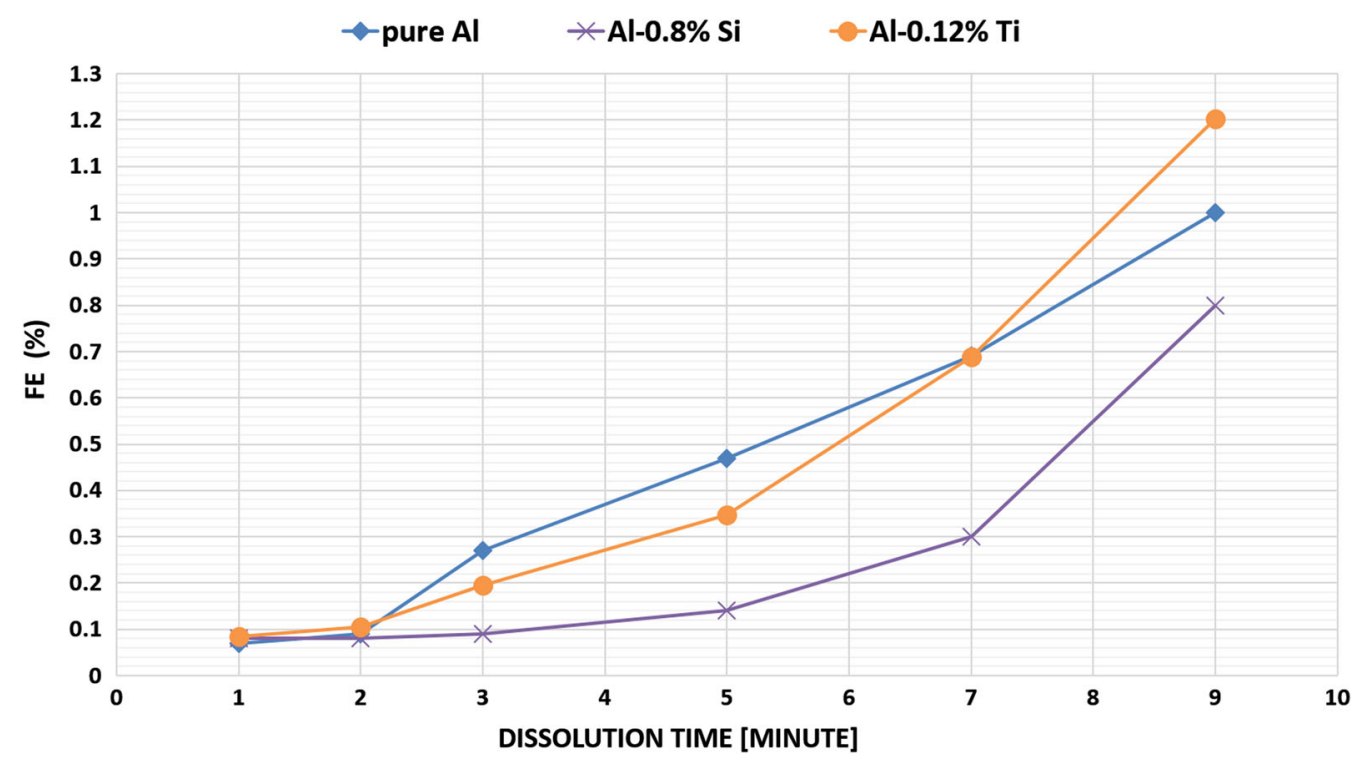

Fig. 11-Fe content of the melt during dissolution as a function of time after the addition of the Fe flakes into the melts with three various compositions and a 3-s stirring.

the iron and a thin layer at the liquid side. The thick phase grew towards the Fe flake, exhibiting an uneven interface which has been previously observed in several investigations ${ }^{[5,8,12,13]}$ and is generally referred to as the saw-teeth morphology. The chemical composition analysis by EDX line scans shows that the composition of this dominating phase is $\mathrm{Al}_{5} \mathrm{Fe}_{2}$, while that of the minor phase (adjacent to the liquid) is $\mathrm{Al}_{3} \mathrm{Fe}$. The latter is identical to what has been reported in previous papers. ${ }^{[5,8,12,13]}$ However, according to our observations, the $\mathrm{Al}_{5} \mathrm{Fe}_{2}$ phase also formed along the grain boundaries inside the Fe flake.

As shown in Figure 13, during the dissolution of Fe in Al-Ti (0.12 pet Ti), two layers formed around the iron flake: an inner layer adjacent to $\mathrm{Fe}$ with a relatively smooth surface and a thick outer layer adjacent to the liquid with a mushy morphology. This indicates that the morphology of the phase at the Fe interface has a less characteristic saw-teeth appearance compared to that in pure Al. According to the composition analysis, the phase adjacent to $\mathrm{Fe}$ is $\mathrm{Al}_{2} \mathrm{Fe}$, i.e., it differs from the one observed in pure Al. The measurements of the outer layer show significant fluctuations due to the mushy morphology and cannot be accurately defined. In addition, the remaining $\mathrm{Fe}$ phase, seen as the white areas, contains a large amount of dissolved $\mathrm{Al}$ (approximately $40 \mathrm{wt} \mathrm{pct}$ ), which corresponds to the $\mathrm{FeAl}$ phase, and the $\mathrm{Al}_{2} \mathrm{Fe}$ phase has grown along the grain boundaries inside the Fe flake. It can be concluded that the addition of $\mathrm{Ti}$ has led to the formation of an additional stable phase and hence influenced the morphology without altering the dissolution rate (Figure 11).

The results of the dissolution of a Fe flake in Al-Si (0.8 pct Si) shown in Figure 14 reveal an altered dissolution behavior. A significant portion of the $\mathrm{Fe}$ flake has remained unreacted in $\mathrm{Al}-\mathrm{Si}(0.8 \mathrm{pct} \mathrm{Si})$ after 8 minutes compared to pure $\mathrm{Al}$ and $\mathrm{Al}-\mathrm{Ti}(0.12$ pct $\mathrm{Ti})$.
In addition, the dissolution took place by forming a layer which was identified by the EDX line scan as a ternary intermediate phase with an average composition of 60 wt pet $\mathrm{Al}, 38$ wt pet $\mathrm{Fe}$, and 2 wt pet $\mathrm{Si}$ (Figure 14(b)).

Moreover, the Fe flakes were not broken and retained their rigidity in contrast to what was observed in pure Al and Al-Ti (0.12 pet Ti) where the flakes disintegrated into small pieces and the newly formed phases penetrated the grain boundaries.

\section{H. Comparison Between the Dissolution of Mn and Fe Flakes in Pure Al}

According to the results of the dissolution rates of the pure $\mathrm{Fe}$ and $\mathrm{Mn}$ flakes in the pure Al melt with the target concentration of 1.5 pct shown in Figure 15, Fe exhibited a higher dissolution rate. In addition, the comparison between the $\mathrm{Mn}$ and Fe dissolution mechanisms shows the creation of different morphologies during the reactions (Figures 7 and 12, respectively). During Mn dissolution, three intermediate phases with smooth interfaces are created, namely, $\gamma 2, \mathrm{Al}_{11} \mathrm{Mn}_{4}$, and the $\mu$ phase. The $\mathrm{Al}_{11} \mathrm{Mn}_{4}$ and $\mu$ phases exhibited a higher growth, while the $\gamma^{2}$ layer remained thin (Figure 4(b)). It seems that these intermediate phases form quickly and simultaneously expand inwards as a package and grow slowly in thickness (Figure 3). Conversely, the Fe dissolution takes place through the formation of two intermediate phases: a dominant phase exhibiting a rough interface $\left(\mathrm{Al}_{5} \mathrm{Fe}_{2}\right)$ which grows quickly towards the $\mathrm{Fe}$ flake forming a saw-teeth morphology and a minor phase $\left(\mathrm{Al}_{3} \mathrm{Fe}\right)$ at the liquid interface (Figure 12(b)).

It is important to note that the Mn flakes were manufactured by casting from a melt while the Fe flakes were compacted $\mathrm{Fe}$ powder, i.e., the $\mathrm{Fe}$ flakes were brittle and could possibly disintegrate and disperse 


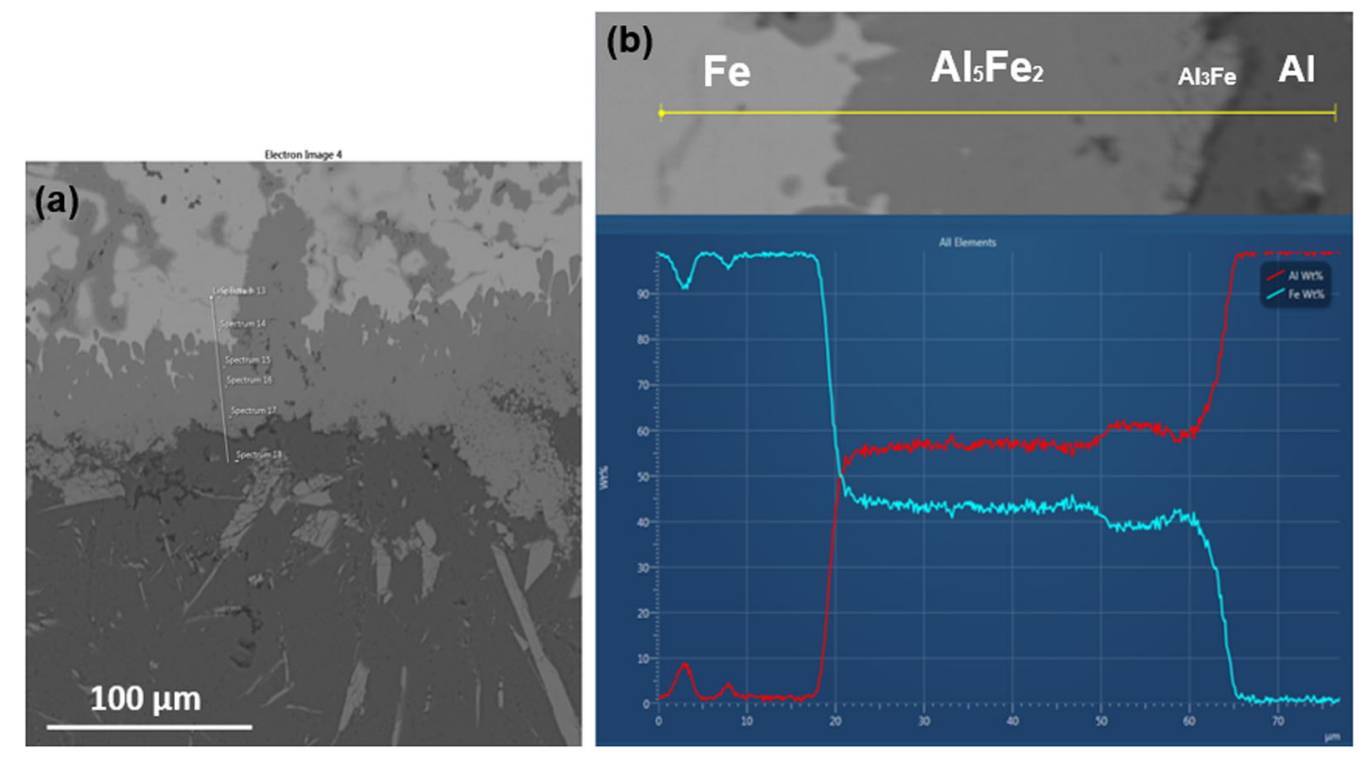

Fig. 12 - (a) Intermetallic phases formed between the interface of a Fe flake and pure liquid $\mathrm{Al}$ after 8 min, $(b)$ corresponding EDX line scan. Full scale $100 \mathrm{wt}$ pct.
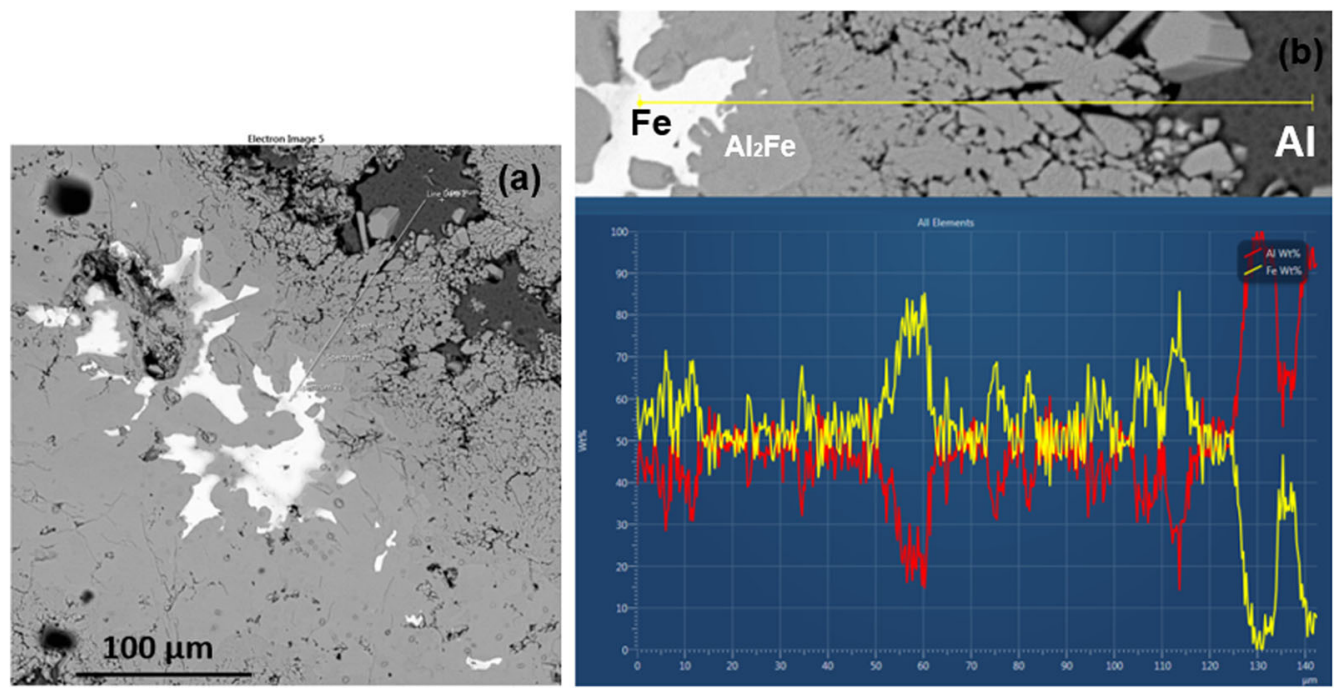

Fig. 13 - (a) Intermetallic phases formed at the interface between a Fe flake and liquid Al-Ti (0.12 pct Ti) after 8 min, $(b)$ corresponding EDX line scan. Full scale 100 wt pct.

inside the melt. The Fe curve shown in Figure 15 is similar to that of the 90 pct Mn compacts shown in Figure 1. Both of these materials were added to the $\mathrm{Al}$ melt in the form of compacted powders.

\section{Precipitations at the Bottom of the Crucible}

In a previous work, ${ }^{[1]}$ the precipitation of a new AlMnTi phase was observed in Al-Mn alloys in the presence of $\mathrm{Ti}$. Therefore, the present study also investigated the precipitations in the $\mathrm{Al}-\mathrm{Ti}(0.12 \mathrm{pct} \mathrm{Ti})$ melt after the addition of $\mathrm{Mn}$. The melt remaining in the crucible after the dissolution-rate test of $\mathrm{Mn}$ in Al-Ti $(0.12$ pct Ti) was studied after it solidified. During the sampling for the dissolution-rate measurements, the melt level decreased, leaving behind only one-third of the original amount of melt. This resulted in the enrichment of $\mathrm{Mn}$ and achieved saturation conditions, i.e., a concentration higher than the targeted one of 1.5 pct Mn. In the SEM image shown in Figure 16, a high number of particles can be seen accumulated at the bottom of the crucible. These particles were identified by EDX as undissolved Mn (Figure 17). The complete EDX line scan shows two plateaus and a gradient characterizing the rest of the Mn particle. No clear distinction between the regions can be observed. Nevertheless, the concentration values indicate the presence of the same intermediate phases as were described in the other $\mathrm{Mn}$ dissolution tests, i.e., $\gamma 2$ adjacent to $\mathrm{Mn}$ followed by the $\mathrm{Al}_{11} \mathrm{Mn}_{4}$ and $\mu$ phases. In addition, 

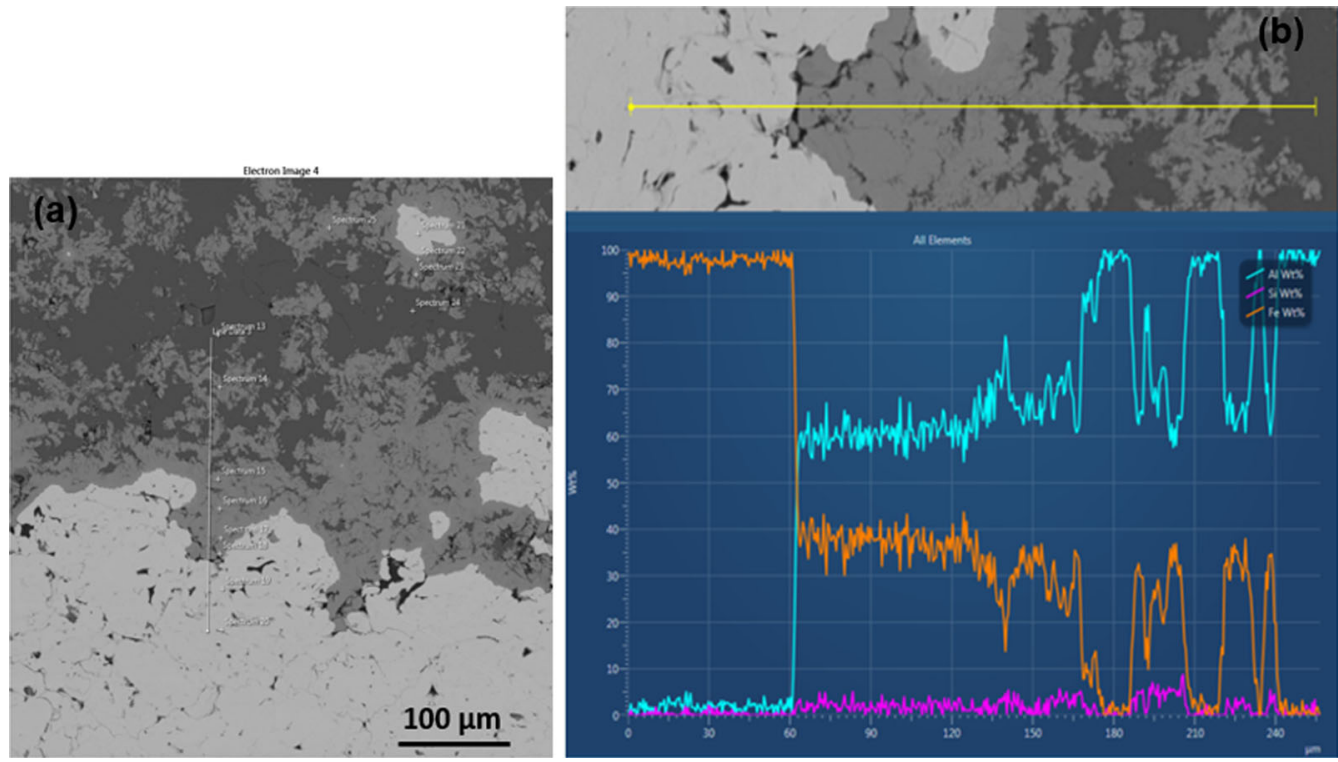

Fig. 14 - (a) Intermetallic phases formed at the interface between a Fe flake and liquid Al-Si (0.8 pct $\mathrm{Si})$ after 8 min, $(b)$ corresponding EDX line scan. Full scale 100 wt pct.

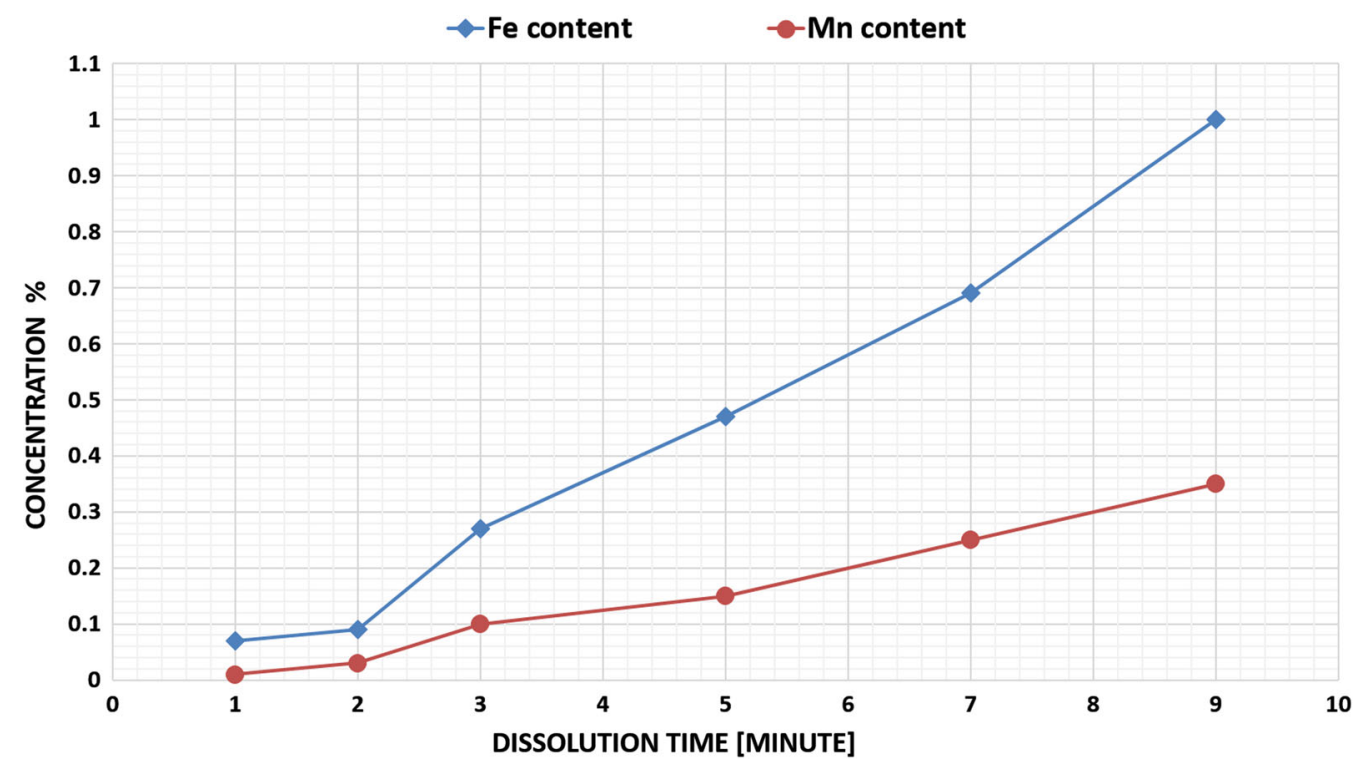

Fig. 15- Fe and Mn contents of the pure Al melt during dissolution as a function of time after the alloying addition.

numerous precipitates were observed in the $\mathrm{Al}$ matrix in the bottom region of the crucible which indicates that supersaturated conditions dominated the cooling process. EDX spectra show that these particles exhibit various compositions: $\mathrm{Al}_{6} \mathrm{Mn}, \mathrm{Al}_{6}(\mathrm{Mn}, \mathrm{Fe})$, $\mathrm{AlMnTi}$, and $\mathrm{Al}_{3} \mathrm{Ti}$ (Figure 18).

\section{DISCUSSION}

\section{A. Dissolution Rate}

The results obtained from the investigation of the dissolution rates (Figure 1) show that the target concentration (1.5 pct Mn) is approached only at the end of the test with the 80 pct Mn with flux. The final shape of the graphs is the result of two processes: the removal of the melt and the increased concentration. The latter was caused by both the decreased amount of melt and the increased $\mathrm{Mn}$ content resulting from the dissolution. Only the dissolution curves of the 80 pct Mn compacts exhibited parabolic behavior towards the end of the dissolution tests which is a marker of reaching the saturation level of 2 pct.

In addition, Figure 1 clearly shows a significantly enhanced dissolution rate with the increasing $\mathrm{Al}$ content of the compacts. As has been discussed in Reference 1, the dissolution of the compacts occurs through several steps: when the compact reaches the melting point of 
aluminum (incubation time), the compacts disintegrate and disperse into the melt for further dissolution. Therefore, compacts with a higher Al content disintegrate more easily, which facilitates the dissolution process and enhances the dissolution rate.

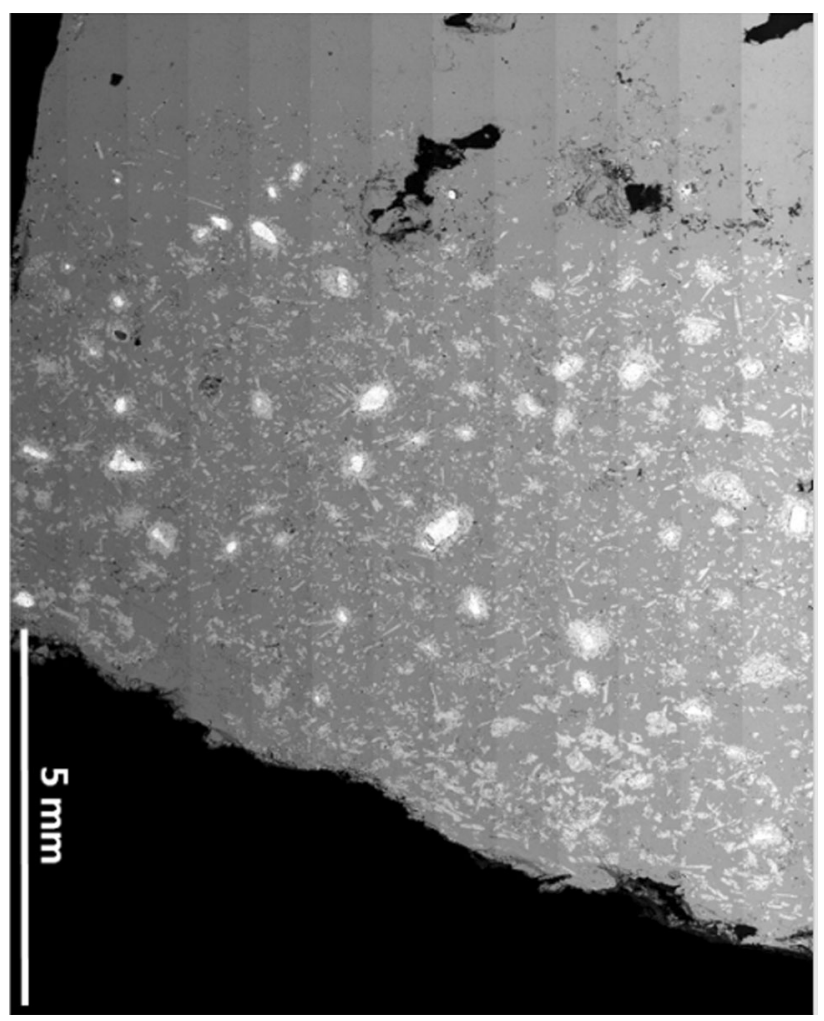

Fig. 16-SEM image of the bottom of the crucible after a $\mathrm{Mn}$ dissolution-rate test in the Al-Ti (0.12 pct Ti) melt. Overview of left lower corner of the crucible, where the white areas are floating undissolved particles.

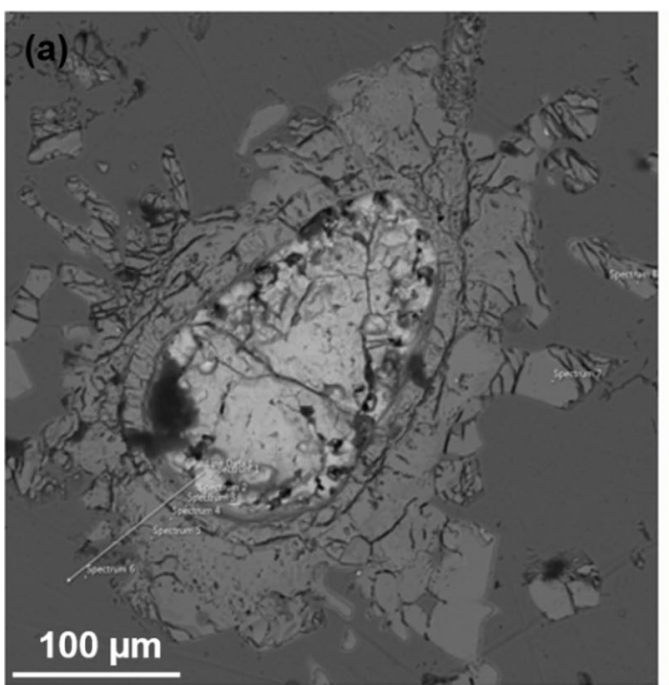

A comparison of the dissolution rates of $\mathrm{Mn}$ compacts and Mn flakes reveals that the dissolution rate of the former is higher than that of the latter. It is obvious that the compacts disintegrate and undergo an exothermic reaction which strongly enhances the dissolution process that continuous surrounding the fragments. It can also be seen in Figure 16 that at the end of the dissolution process, the dissolving particles seem to be floating in the melt despite being heavier. This suggests that natural convection moves the dissolving particles around in the liquid, which further increases the dissolution rate.

The flakes maintain their shape and only react at their original surface, which will be significantly smaller than the total area of the particles in the compact. Moreover, the flakes will preferably move towards the bottom of the crucible. The dissolution-rate difference coupled with the area and particle size is further discussed in conjunction with the theoretical treatment of the dissolution rates below.

\section{B. Theoretical Approach}

The dissolution of alloying elements is mass-transfer controlled. Calculations of the Mn and Fe fluxes in the two systems studied in this work were carried out in Reference 1 where the authors assumed the presence of only one intermediate phase, and in the literature a number cases, from different alloy systems, have been discussed where only one intermediate phase appears. $^{[14-17]}$ However, several phases have been observed in the present investigation, especially in the Al-Mn system where two phases, $\mathrm{Al}_{11} \mathrm{Mn}_{4}$ and $\mu$, exhibited a similar thickness with a third phase, $\gamma 2$, being somewhat thinner. This significantly complicates the diffusion problem as it is not possible to identify a single dominating phase, making the assumption of the flux being determined by the transport in that phase invalid. Moreover, the diffusion coefficients in the different phases are unknown.

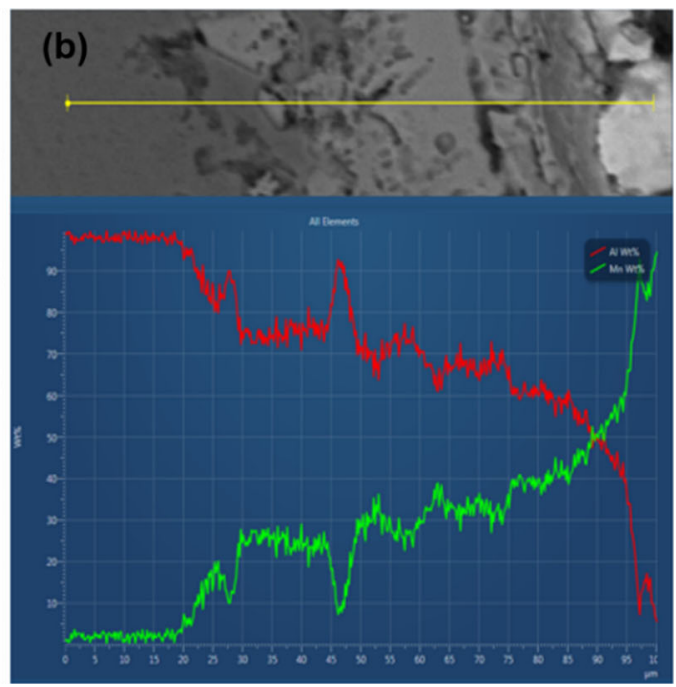

Fig. 17-(a) Intermetallic phases formed around an undissolved Mn particle in an Al-Ti $(0.12$ pct Ti) melt. The sample was taken from the bottom of the crucible after $9 \mathrm{~min}$ of dissolution and cooling at ambient temperature, $(b)$ corresponding EDX line scan. 

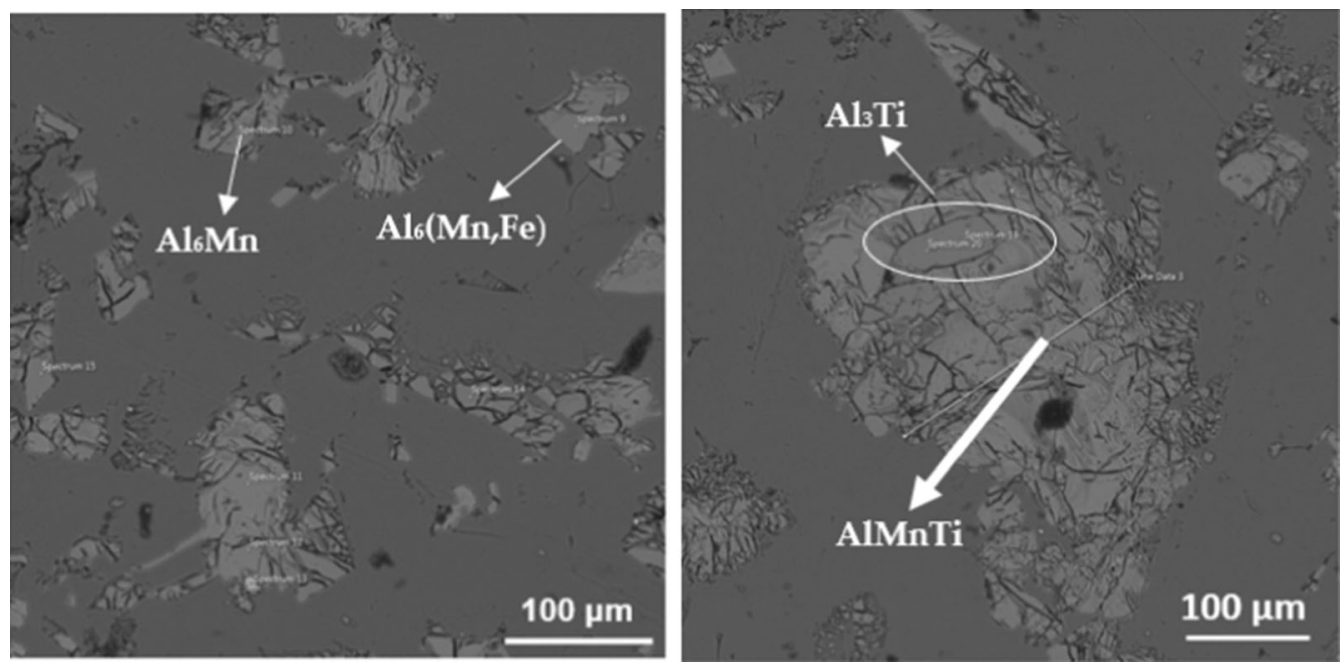

Fig. 18-SEM image of the precipitate in the Al-Ti (0.12 pct Ti) obtained from the bottom of the crucible (lower part of Fig. 16) after 9 min of dissolution.

However, it is possible to theoretically analyze the flux in the melt using the dissolution-rate data which determine the flux into the melt for the various cases. This is important as it was shown in both the present study and in Reference 1 (as well by industrial experience) that stirring and the subsequent melt transport influence the dissolution rate. The flux of $\mathrm{Mn}$ and $\mathrm{Fe}$ into the Al melt can be obtained by Ficks' law of diffusion over a boundary layer with a thickness of $\delta$ in the liquid adjacent to the dissolving particles, as described by Eq. [1]:

$$
\mathrm{d} m / \mathrm{d} t=-D A \mathrm{~d} c / \mathrm{d} y,
$$

where $\mathrm{dm} / \mathrm{dt}$ is the flux passing through the surface area $A, D$ is the diffusion coefficient, and $\mathrm{d} c / \mathrm{d} y$ is the concentration gradient driving the flux, where $\mathrm{d} c$ is $\Delta \mathrm{c}=\mathrm{c}^{\mathrm{eq}}-\mathrm{c}^{\mathrm{l}}$, i.e., the saturation level minus the concentration in the liquid. If $\mathrm{m}$ is measured in weight and dc in wt pct, the equation can be rewritten as

$$
\mathrm{d} m / \mathrm{d} t=-(D A / 100) r D c / \delta,
$$

where $\rho$ is the density and $\delta$ is the diffusion boundary layer thickness in the liquid. From Figure 15, it is possible to attain the concentration of $\mathrm{Mn}$ and $\mathrm{Fe}$ in the liquid $\mathrm{Al}$ after 9 minutes, namely, 0.35 and $1 \mathrm{wt}$ pct, respectively. The obtained flux is $3.2 \times 10^{-3}$ and $9.2 \times$ $10^{-3} \mathrm{~g} / \mathrm{s}$ into a $500 \mathrm{~g}$ melt for $\mathrm{Mn}$ and Fe, respectively. The saturation level, $\mathrm{c}^{\mathrm{eq}}$, of $\mathrm{Mn}$ and $\mathrm{Fe}$ in the aluminum can be taken from the phase diagrams to be $8 \mathrm{wt} \mathrm{pct}^{[6]}$ and $5 \mathrm{wt} \mathrm{pct,}{ }^{[5]}$ respectively, at $750{ }^{\circ} \mathrm{C}$, and $\mathrm{c}^{1}$ can be approximated as zero. The diffusion coefficients used for $\mathrm{Mn}$ and $\mathrm{Fe}$ in liquid $\mathrm{Al}\left(720^{\circ} \mathrm{C}\right)$ were $0.85 \times 10^{-9}$ and $1.95 \times 10^{-9} \mathrm{~m}^{2} / \mathrm{s}$, respectively. ${ }^{[1]}$ The density of aluminum was assumed to be $2600 \mathrm{~kg} / \mathrm{m}^{3}$, and the contact area, A, of the alloying elements was taken as $10 \mathrm{~cm}^{2}$ based on the size and number of the flakes added to the melt. The diffusion boundary layer thickness is directly related to the liquid flow, i.e., to the stirring. Assuming the presence of similar convection conditions, the thicknesses should be the same for both $\mathrm{Mn}$ and Fe. By Eq. [2] it is thus possible to calculate the ratio between the dissolution of $\mathrm{Mn}$ and $\mathrm{Fe}$, and thus determine that the Fe flux is 1.4 times larger. The experimental results, however, show that the ratio is about 2.9. This difference could possibly be caused by different surface areas, since the Fe flakes seem to disintegrate into smaller particles, thus having a higher surface area for the reaction. During the dissolution process, Al was observed to penetrate the grain boundaries (Figure 12(a)) possibly as the result of these flakes being made of compacted powder. The more rigid as-cast Mn flakes maintain their structure and only react at their surface. The same effect was observed when the dissolution of $\mathrm{Mn}$ compacts was compared to the dissolution of Mn flakes, as was discussed above and can be seen in Figure 1.

From Eq. [2], it is also possible to calculate the boundary layer thickness, $\delta$. The latter can be used to determine the rate constant, $\mathrm{k}$, of the dissolution process:

$$
k=D / \delta
$$

A value of $1.5 \times 10^{-5} \mathrm{~m} / \mathrm{s}$ is obtained for $\mathrm{Mn}$, which can be compared to results presented in Reference 1 where rate constants were calculated for different stirring conditions. The obtained value fits well to the intermediate stirring conditions described in Reference 1.

The effect of stirring can be studied by comparing Figure 1 (3-second stirring) to Figure 2 (5-second stirring) where the dissolution rate of $\mathrm{Mn}$ has substantially increased in the latter if only the pure $\mathrm{Al}$ melt is considered. This shows the importance of stirring for the dissolution performance. It can be concluded that the stronger convection prevailed during the test with 5 -second stirring, thus achieving an enhanced mass transfer between the $\mathrm{Mn}$ and the Al bulk and subsequently a higher dissolution rate. 


\section{Dissolution Mechanisms and Intermediate Phases}

The transformation of the alloying elements from their initial solid state at $750{ }^{\circ} \mathrm{C}$ into a liquid solution occurs via the formation of several intermetallic phases that form between the alloying elements and the $\mathrm{Al}$ liquid under conditions described by the equilibrium phase diagrams. Thus, direct dissolution of the pure solid phase in liquid $\mathrm{Al}$ is replaced by the formation and dissolution of the intermediate phases.

The dissolution mechanism tests showed that the intermediate phases around the $\mathrm{Mn}$ compact particles were thicker ( $\sim 50 \mu \mathrm{m}$, Figures 4(a) and 6(a)) than the intermediate phases formed around the flakes $(\sim 20 \mu \mathrm{m}$, Figures 7(a) and 8(a)). The higher dissolution rate of Mn compacts compared to the flakes has been discussed above based on the transport of Mn into the liquid, where possibly both the surface area and shape of the particles have a significant influence. It is likely that a faster transport of $\mathrm{Mn}$ from the surface drives the increased dissolution rate of $\mathrm{Mn}$ through the layers of the intermediate phases and thus causes the reactions to accelerate, subsequently forming thicker layers. A higher flow increases the $\mathrm{Mn}$ content in the melt in the vicinity of the particles and can locally cause supersaturation and thus a faster growth of the outer $(\mu)$ phase into the liquid. This subsequently leads to the formation of thicker layers. An example can be seen in Figure 10(b), where an oxide film prevents the mixing of the solute, allowing the $\mu$ phase to reach a greater thickness in the left side of the figure.

The dissolution tests of $\mathrm{Mn}$ in $\mathrm{Al}$ melts suggest that the intermediate phases reach a certain thickness rather quickly, followed by a slow growth in the form of a package penetrating into the particle during dissolution (Figure 10) without any clear increase in thickness (Figure 3). This probably means that the flux of $\mathrm{Al}$ atoms through the layer and towards the solid $\mathrm{Mn}$ is slower than the flux of $\mathrm{Mn}$ atoms towards the liquid, as the opposite would lead to the growth of the $\gamma^{2}$ phase into $\mathrm{Mn}$. This causes the formation of voids in the $\beta$-Mn close to the $\gamma_{2}$ interface, which can be seen in several figures, e.g., Figures 3 and 4. This phenomenon is known as the Kirkendall effect. ${ }^{[17-19]}$ Figure 3 clearly shows the increasing number and size of the voids during the diffusion process. These phenomena will decrease the area and bond between the inner intermediate phase $\gamma_{2}$ and $\beta$-Mn and inhibit further growth and dissolution. ${ }^{[18]}$

In every Mn dissolution experiment, three intermediate phases with smooth interfaces have formed between $\mathrm{Mn}$ and the liquid, namely, $\gamma 2, \mathrm{Al}_{11} \mathrm{Mn}_{4}$, and the $\mu$ phase. The $\gamma 2$ phase was noticeably thinner compared to the $\mathrm{Al}_{11} \mathrm{Mn}_{4}$ and $\mu$ phases, with the thickness of the latter two being approximately equal (Figures 4, 7, and 8). According to the Al-Mn phase diagram, $\mathrm{Al}_{11} \mathrm{Mn}_{4}$ is stoichiometric and the $\mu$ phase has a narrow solubility range. The concentration profiles obtained by EDX line scans also showed plateaus for these phases. The $\gamma 2$ phase and $\beta \mathrm{Mn}$ phase are characterized by large solubility ranges. Both exhibited steep concentration gradients in the line scans (Figures 6(b) and 7(b)).

Figure 19 schematically illustrates the phases at the interface between $\mathrm{Mn}$ and liquid $\mathrm{Al}$ where the relative thicknesses are drawn based on the results in Figures 4, 7 , and 8 . The levels in the line scans and the occurrence of plateaus and gradients clearly define the phases. Although the EDX data can be unreliable for defining the individual phases, the total picture from every scan in combination with the phase diagram strongly supports the phase identification.

During stationary diffusion, the flux is determined by the phase with the largest $\mathrm{D} \Delta \mathrm{c}$ which presents the smallest resistance to the diffusion. This phase generally becomes the thickest. In the investigated system, two phases are dominating, $\mathrm{Al}_{11} \mathrm{Mn}_{4}$ and $\mu$, although they exhibit small solubility ranges, i.e., $\Delta \mathrm{c}$ values, while the $\gamma 2$ phase with a large $\Delta \mathrm{c}$ is relatively thin. The diffusion coefficients of the thicker phases can thus be concluded to be larger than that of the $\gamma 2$ phase, which will thus be the largest obstacle for diffusion flow.

Comparing the dissolution of pure Mn with that of the 60 pet Mn alloy, which is in $\gamma 2$ from the beginning, shown in Figures 7 and 9, respectively, no pores form in the 60 pet Mn alloy. This suggests that Al diffusion to the interface of the $\gamma 2$ phase is fast enough to balance the outwards Mn diffusion to form a new phase instead of forming pores. This supports the conclusion above that the $\gamma 2$ phase was the main obstacle for Al diffusion, as in the 60 pct $\mathrm{Mn}$ alloy, $\mathrm{Al}$ does not need to diffuse through the $\gamma 2$ phase.

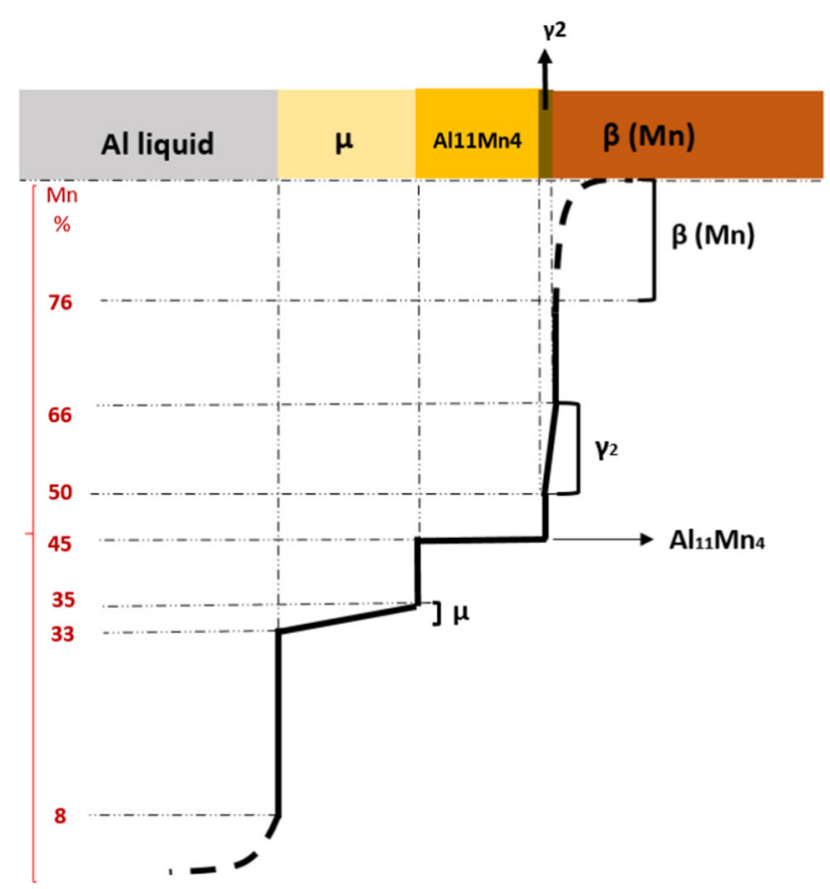

Fig. 19-Schematic of the intermetallic phase growth at the interface of $\mathrm{Mn}$ and $\mathrm{Al}$ liquid at $750^{\circ} \mathrm{C}$. 
The oxide layers formed at some spots during the dissolution of 60 pct Mn flakes prevented any reaction (Figure 10(b)). Moreover, a thick intermediate phase formed where the liquid was trapped between the oxide and the dissolving $\mathrm{Mn}$ particle (left part of Figure 10(b)). This illustrates the role of convection: the oxide hindering the mixing of the melt adjacent to the interface leads to the supersaturation of the liquid and the subsequent growth of the phase outwards.

During the dissolution of $\mathrm{Fe}$ in the pure $\mathrm{Al}$ melt, a single intermediate phase $\left(\mathrm{Al}_{5} \mathrm{Fe}_{2}\right)$ dominates the process, which grows within the $\mathrm{Fe}$ solid exhibiting a saw-teeth morphology (Figure 12). This indicates that the flux of the $\mathrm{Al}$ atoms towards $\mathrm{Fe}$ through the intermetallic phase is faster than the flux of $\mathrm{Fe}$ atoms towards the liquid. Therefore, no porosity is created, i.e., there is no Kirkendall effect present, and a relatively fast transformation of the original pure Fe into $\mathrm{Al}_{5} \mathrm{Fe}_{2}$ takes place. The observations in this work regarding $\mathrm{Fe}$ dissolution are similar to what has been discussed thoroughly in the literature ${ }^{[5,7,12,13]}$ and it should only be concluded here that the $\mathrm{Al}_{5} \mathrm{Fe}_{2}$ phase must exhibit the largest $\mathrm{D} \Delta \mathrm{c}$ value in this system.

\section{Transformations During Cooling}

The EDX scans of the phases adjacent to the liquid $\mathrm{Al}$, i.e., between the $\mu$ phase and $\mathrm{Al}$ in Figures 4 and 6, or the outer light green phases in Figure 3 exhibit significant fluctuations and decreased $\mathrm{Al}$ content. These regions are presumably formed during the cooling of the samples and are a mixture of $\mathrm{Al}_{6} \mathrm{Mn}$ and $\mathrm{Al}$. In the $\mathrm{Fe}$ experiments, the corresponding phase is a mixture of $\mathrm{FeAl}_{3}$ and $\mathrm{Al}$. The decreased $\mathrm{Al}$ content observed in these regions is contradictory. However, a close dissemination shows that these phases are cracked and partially missing. Hence, their EDX signal is not reliable, as a significantly lower $\mathrm{Al}$ content was observed at each crack. A possible explanation is the emittance from $\mathrm{Al}$ being more sensitive to the surface flatness than the emittance from the heavier metals.

\section{E. Effect of the Addition of Alloying Elements on the Dissolution of $\mathrm{Mn}$ and Fe}

Figure 2 shows that the dissolution rate of $\mathrm{Mn}$ is significantly decreased by the addition of a small amount of Ti. Moreover, the results of the Mn dissolution from flakes shown in Figures 7 and 8 indicate that the total thickness of the intermediate phases is also decreased by 50 pct by the addition of Ti. It can be concluded that Ti inhibits the dissolution kinetics. A possible explanation for the effect of $\mathrm{Ti}$ on the dissolution rate can be attributed to the very low diffusion coefficient of $\mathrm{Ti}$ in liquid $\mathrm{Al} .{ }^{[1]}$ At a steady state, $\mathrm{Al}$ has to be transported through the liquid boundary layer. If
Ti interacts with the aluminum flux, the total flux may be lowered in the same way as the lower convection can inhibit the dissolution rate by influencing the mass transport in the liquid. ${ }^{[3]}$

It was also shown that the dissolution rate of $\mathrm{Fe}$ in pure $\mathrm{Al}$ was not influenced by the addition of 0.12 pct $\mathrm{Ti}$ to the melt (Figure 11) which is different from what was observed for Mn dissolution. However, the results show that the addition of $\mathrm{Ti}$ has affected the intermetallic compound formation, i.e., the $\mathrm{Al}_{5} \mathrm{Fe}_{2}$ phase was replaced by $\mathrm{Al}_{2} \mathrm{Fe}$, and $\mathrm{Fe}$ had transformed to $\mathrm{FeAl}$ phase after strong aluminum diffusion into the iron flake.

The dissolution rate of $\mathrm{Fe}$ in aluminum containing 0.8 pct $\mathrm{Si}$ is significantly decreased compared to the pure Al. By comparing Figures 12 and 14, it can be concluded that the Fe flakes reacted in thin zones in the Al-Si $(0.8$ pct $\mathrm{Si}$ ) alloy, while thick layers formed around the $\mathrm{Fe}$ flakes in the pure $\mathrm{Al}$, an observation also reported in Reference 20. It can be concluded that the addition of $\mathrm{Si}$ greatly influenced the dissolution kinetics of Fe. This was also discussed in Reference 12, where the authors concluded that the growth rate of the $\mathrm{Al}_{5} \mathrm{Fe}_{2}$ and $\mathrm{Al}_{3} \mathrm{Fe}$ phases is reduced in the presence of $\mathrm{Si}$. In addition, the typical saw-teeth morphology of the $\mathrm{Al}_{5} \mathrm{Fe}_{2}$ phase was not observed after Si addition. This was confirmed by the present study, as shown in Figure 14, where the forming phase also contained approximately 2 pct Si. It is, in this case, difficult to precisely determine which structures are formed in the sample while it is maintained at $750{ }^{\circ} \mathrm{C}$ and which form during the cooling process as the new phases seem to grow towards the liquid.

\section{F. Particles at the Bottom of the Crucible}

At the bottom of the crucible after the dissolution-rate test, partially undissolved particles and intermediate phase particles were found, suspended up to a certain height (Figure 16). An undissolved particle was analyzed with the results shown in Figure 17, which showed similar phases as was observed in the dissolution of compacts in the melt of the same composition (Figure 6), although the intermediate phases were more cracked which reduced the quality of the EDX signal.

Particles not containing undissolved Mn exhibited a different composition (Figure 18) and possibly formed during both the dissolution and the cooling process. The $\mathrm{Al}_{6}(\mathrm{Mn}, \mathrm{Fe})$ phase can be expected to precipitate during the cooling. However, additional phases of $\mathrm{Al}_{3} \mathrm{Ti}$ and AlMnTi were also observed. The formation of the latter was discussed in References 3 and 11 as it is detrimental for rolling operations if it forms in DC cast rolling ingots. It is interesting to note that both phases can form under the present conditions with only 0.12 pct $\mathrm{Ti}$ contained in the melt, but locally elevated 
concentrations of Mn can probably occur during the dissolution process which might influence the solubility limit of $\mathrm{Ti}$. This possibly occurs in industrial holding furnaces during alloying as well.

\section{CONCLUSIONS}

The dissolution processes of $\mathrm{Mn}$ and $\mathrm{Fe}$ in molten $\mathrm{Al}$ alloys were studied through several series of dissolution experiments to investigate the intermetallic compound formation and involved dissolution kinetics.

From the dissolution of $\mathrm{Mn}$ in molten $\mathrm{Al}$, it can be concluded that:

- Three intermediate phases with smooth interfaces have formed between Mn and the liquid, namely, the $\gamma 2, \mathrm{Al}_{11} \mathrm{Mn}_{4}$, and $\mu$ phases. The $\gamma_{2}$ phase formed a noticeably thinner layer compared to the $\mathrm{Al}_{11} \mathrm{Mn}_{4}$ and $\mu$ phases. The latter two formed layers of approximately equal thicknesses.

- It was proposed that the low diffusion coefficient of the $\gamma 2$ phase is the largest obstacle for the diffusion flow of the Al atoms towards the Mn particles, causing a Kirkendall effect with a porous structure at the periphery of the $\mathrm{Mn}$ particle.

- The increasing Al contents in Al-Mn compacts corresponded to higher dissolution rates.

- The effect of stirring on the dissolution performance was demonstrated by tests using different stirring times, where 5-second stirring resulted in a higher dissolution rate than 3 -second stirring.

From the dissolution of $\mathrm{Fe}$ in molten $\mathrm{Al}$, it can be concluded that:

- $\mathrm{Al}_{5} \mathrm{Fe}_{2}$ is the dominating phase during $\mathrm{Fe}$ dissolution and must have the largest $\mathrm{D} \Delta \mathrm{c}$ value in the Al-Fe system.

- The addition of Ti to an $\mathrm{Al}$ melt replaces the $\mathrm{Al}_{5} \mathrm{Fe}_{2}$ phase by $\mathrm{Al}_{2} \mathrm{Fe}$, but does not influence the dissolution rate.

- The addition of Si to an Al melt greatly inhibits the $\mathrm{Fe}$ dissolution kinetics.

A theoretical approach based on Ficks' law showed that the observed difference between the $\mathrm{Mn}$ and $\mathrm{Fe}$ dissolution rates can be explained by the different surface areas involved, as the $\mathrm{Fe}$ flakes seem to disintegrate into smaller particles, thus exposing a bigger surface for possible reactions. The same effect was observed when the dissolution of Mn compacts was compared with the dissolution of Mn flakes.

\section{ACKNOWLEDGMENTS}

The authors acknowledge Sweden's Innovation Agency for their financial support and Kubikenborg Aluminium AB and Gränges Sweden AB for providing materials and for their important input regarding industrial practices.

\section{OPEN ACCESS}

This article is distributed under the terms of the Creative Commons Attribution 4.0 International License (http://creativecommons.org/licenses/by/4.0/), which permits unrestricted use, distribution, and reproduction in any medium, provided you give appropriate credit to the original author(s) and the source, provide a link to the Creative Commons license, and indicate if changes were made.

\section{REFERENCES}

1. A. S. Najafabadi: Ph.D. thesis, McGill University, Canada, 1996, ISBN 0-612-12481-9.

2. Y. E. Lee and S. L. Houser: Light Metals, 2000, TMS, pp. 44-50.

3. G. Razaz, and T. Carlberg: Light Metals, 2016, TMS, pp. 731-36.

4. M. Farhani, M. Soltanieh, and M.R. Aboutalebi: Int. J. Cast Metals Res., 2009, vol. 22.5, pp. 353-56.

5. H.R. Shahverdi, M.R. Ghomashchi, S. Shabestari, and J. Hejazi: J. Mater. Process. Technol., 2002, vol. 124, pp. 345-52.

6. X.J. Liu, I. Ohnuma, R. Kainuma, and K. Ishida: J. Phase Equilib., 1999, vol. 201, pp. 45-56.

7. A. Bouayad, C. Gerometta, A. Belkebir, and A. Ambari: Mater. Sci. Eng. A, 2003, vol. 363, pp. 53-61.

8. K. Bouché, F. Barbier, and A. Coulet: Mater. Sci. Eng. A, 1998, vol. 249 , pp. $167-75$.

9. H. Rezaei, M.R. Akbarpour, and H.R. Shahverdi: JOM, 2015, vol. 67 , pp. $1443-50$.

10. D. Naoi and M. Kajihara: Mater. Sci. Eng. A, 2007, vol. 459, pp. 375-82.

11. G. Razaz and T. Carlberg: Conference on Solidification Processing, 2017, vol. 6th Decennial, pp. 180-83.

12. F. Yin, M. Zhao, Y. Liu, W. Han, and Z. Li: Trans. of Nonferr. Metals Soc. China, 2013, vol. 23, pp. 556-61

13. N. Takata, M. Nishimoto, S. Kobayashi, and M. Takeyama: Intermetallics, 2015, vol. 67, pp. 1-11.

14. C. Wagner: Acta Metall., 1969, vol. 17, pp. 99-107.

15. F.J.J. van Loo and G.D. Rieck: Acta Metall., 1973, vol. 21, pp. 61-71.

16. V.I. Dybkov: J. Mater. Sci., 1986, vol. 21, pp. 3078-84

17. G.V. Kidson and G.D. Miller: J. Nucl. Mater., 1964, vol. 12, pp. 61-69.

18. M.H.J. van Dal: PhD thesis, Technische Universiteit Eindhoven, Netherlands, 2001, ISBN 90-386-2982-6.

19. Z. Shi, H. Wei, H. Zhang, T. Jin, X. Sun, and Q. Zheng: Int. J. Refract. Metals Hard Mater., 2016, vol. 60, pp. 108-12.

20. G. Eggler, W. Auer, and H. Kaesche: J. Mater. Sci., 1986, vol. 21, pp. 3348-50. 